\title{
REVISIÓN DE LA TUTELA JURÍDICA DEL ASEGURADO EN EL DERECHO CHILENO: UN ANALISIS CRÍTICO AL MARCO JURÍDICO APLICABLE
}

\author{
REVIEW OF THE LEGAL PROTECTION OF THE INSURED \\ UNDER CHILEAN LAW: A CRITICAL ANALYSIS OF THE \\ APPLICABLE LEGAL FRAMEWORK
}

MARÍA FERNANDA VÁSQUEZ PALMA * **

\section{RESUMEN}

Reconociendo que el seguro se plasma normalmente en un contrato de adhesión y que los asegurados son, por regla general, consumidores, el legislador chileno modificó la normativa de seguro en 2013 a partir de la dictación de la Ley $\mathrm{N}^{\mathrm{0}} 20.667$, insertando algunos mecanismos de protección del contratante débil, entre los que destacan: la imperatividad (artículo 542 del Código de Comercio) la configuración y el depósito de pólizas, y un cauce procesal para hacer valer sus derechos, etc. Luego de analizar el estatuto jurídico en su conjunto, hemos de llegar a la conclusión de que la protección brindada es feble, desarticulada e ineficiente, lo que permitiría afirmar que la reforma de 2013 en materia de seguros no alcanzó el objetivo trazado. Nos proponemos develar las razones que subyacen en ello, para finalizar con algunas propuestas de solución.

Palabras clave: Contrato de seguro, Contrato de adhesión, Consumidor, Imperatividad, Derecho del consumo, Estatuto protector chileno.

* Profesora Titular, Facultad de Ciencias Jurídicas y Sociales, Universidad de Talca, Talca, Chile. Doctora en Derecho, Universidad Complutense de Madrid, España. Correo electrónico: mfvasquez@ utalca.cl. ORCID: https://orcid.org/0000-0002-2861-5520.

** Agradecimientos a mi ayudante de investigación Gloria Vargas Almonacid.

Artículo recibido el 3 de noviembre de 2020, y aprobado para su publicación el 15 de junio de 2021 . 


\section{ABSTRACT}

Recognizing that insurance is normally embodied in a contract of adhesion and that insured persons are generally consumers, the Chilean legislator amended the insurance regulations in 2013, starting with the issuance of Law 20.667, inserting some tutelary mechanisms of the weak contractor, among which stand out: the imperative (article 542 of the Code of Commerce, hereinafter Cco.), the configuration and deposit of policies, a procedural channel such as arbitration, etc. However, after analyzing the legal status as a whole, we have to conclude that the protection provided is fair, disjointed and inefficient, which would allow us to affirm that the 2013 reform in the field of insurance did not achieve the goal set. For this reason, we intend to unveil the reasons behind this, to conclude with some proposals for a solution.

Keywords: Insurance contract, Contract of adhesion, Consumer, Imperativity, Consumer law, Chilean protective statute.

\section{INTRODUCCIÓN}

La construcción del contrato es normalmente un campo abierto para la autonomía de la voluntad, pero este principio no siempre se puede ejercer, tampoco en lo que denominamos derecho privado, pues la libertad, para que sea tal, requiere un terreno abonado. Este no existe, por ejemplo, cuando la capacidad negociadora de una de las partes se encuentra disminuida o derechamente anulada, como ocurre con la suscripción de un contrato por adhesión, pues en este formato se presenta una notoria asimetría negocial entre las partes: una de ellas es quien preestablece las condiciones y la otra sólo se limita a aceptarlas o rechazarlas.

En este escenario, el legislador debe instaurar ciertos resguardos de orden público en aras a impedir que los sujetos adherentes sufran abusos y/o atropellos en sus derechos y, subsecuentemente, el mercado sufra perniciosas consecuencias. Debido a ello, el aparato legislativo se encuentra obligado a diseñar ciertas herramientas jurídicas que sirvan de freno y protección en favor del contratante débil. Cada legislador plantea sus propias herramientas, pero es común observar la creación de normas imperativas o irrenunciables para el contratante débil; cargas y obligaciones precontractuales que debe 
asumir el predisponente en mayor medida que el adherente; determinadas exigencias y controles que se deben cumplir al confeccionar el contrato de adhesión; cauces procesales para hacer valer sus derechos, entre otras.

Sobre esta base, y reconociendo que los asegurados son contratantes débiles en el contrato de seguro, el legislador decidió incorporar, a partir de la Ley N 20.667 de 2013, algunos de estos mecanismos con el objeto de fortalecer el estatuto jurídico protector de estos sujetos. ${ }^{1}$

La doctrina ha analizado parte de estas materias, sin embargo, no existe un análisis crítico como el que aquí se propone, de manera que esperamos que este texto constituya un modesto aporte al estudio de estos mecanismos. La cuestión es relevante, toda vez que siendo el contrato de seguro normalmente de adhesión, dónde lo más relevante gira en torno a la selección y antiselección de riesgos, en que la aseguradora es la entidad profesional que redacta el contrato y el asegurado normalmente decide en base a sus propias necesidades, pero sin contar con una visión holística ni mentada sobre aquella, corresponde revisar si el marco jurídico instaurado se hace cargo de estas asimetrías y cómo.

En el presente texto, junto con identificar y analizar tres de estos mecanismos (imperatividad normativa, construcción y control de la póliza, y cauce procesal), avanzaremos un paso más al cuestionar si estos constituyen un real progreso en la protección del asegurado-consumidor, determinando las debilidades de la regulación actual. Nuestra hipótesis propone que estas herramientas no son eficientes, ${ }^{2}$ de manera que la tutela jurídica del asegurado incorporada por la Ley 20.667 no es consistente y debiese modernizarse, pues no está a la altura de lo esperado. En las siguientes líneas se analizarán las razones de ello y una propuesta interpretativa y de lege ferenda a modo de solución.

\footnotetext{
${ }^{1}$ Antes de la reforma introducida por la Ley 20.667, de 2013, al contrato de seguro, las normas que regulaban este instituto, por regla general, eran de carácter dispositivo.

${ }^{2}$ En relación a la etapa precontractual puede consultarse: BARRIEntos, M., "Artículo 529 n. ${ }^{\circ}$ 1: Obligaciones del asegurador (el deber precontractual de información)", en Ríos, R. (Dir.), El contrato de seguro. Comentarios al Título VIII Libro II del Código de Comercio, Thomson Reuters, Santiago, 2015, pp. 334-360; Ríos, Roberto, "El deber de información en el seguro como instrumento de decisión racional en la contratación y de tutela a favor del asegurado", Revista de Derecho Privado, 2020, n. ${ }^{\circ}$ 39 (jul-dic), pp. 203-231; De LA MAZA, I., "El suministro de información como técnica de protección de los consumidores: los deberes precontractuales de información", Revista de Derecho Universidad Católica del Norte, 2010, año 17, n. ${ }^{\circ}$ 2, pp. 21-52; Ríos Ossa, R., "El deber de información en el seguro como instrumento de decisión racional en la contratación y de tutela a favor del asegurado", Revista de Derecho Privado, 2020, №39, pp. 203-231.
} 


\section{PROTECCIÓN DEL CONTRATANTE DÉBIL EN EL CONTRATO POR ADHESIÓN}

\subsection{Consumo, protección del consumidor y contratos por adhesión}

El acto de consumo es un acto jurídico bilateral (o multilateral), oneroso o gratuito, ${ }^{3}$ realizado por un sujeto de derecho que pretende adquirir, utilizar o disfrutar de un bien o servicio como destinatario final, y ello ocurre dentro de los contornos materiales de la Ley 19.496, de 1997 de que establece normas sobre protección de los derechos de los consumidores (LPC). ${ }^{4-5}$ Participan dos sujetos: proveedor y consumidor, ${ }^{6}$ el primero puede ser una persona natural o jurídica, incluyendo las micro y pequeñas empresas, ${ }^{7-8}$ que sean destinatarios finales de los productos; ${ }^{9}$ el segundo realiza habitualmente actividades de producción, fabricación, construcción, comercialización, prestación de servicios, etc., cobrando un precio por ello. ${ }^{10}$

\footnotetext{
${ }^{3}$ Si bien la LPC se refiere a la onerosidad como requisito en la noción de consumidor, actualmente la doctrina se encuentra conteste en que no se requiere ni siquiera de celebración de acto jurídico para que se presente una relación de consumo. Lo mismo respecto de los actos onerosos. En tal sentido, la degustación gratuita en un supermercado también está asilada por la LPC.

${ }^{4}$ Esta normativa fue modificada por última vez a partir de la Ley No 21.081, de 2018.

${ }^{5}$ En cuanto al ámbito de aplicación de esta norma, puede consultarse en Chile a: IsLER, Erika, Derecho del consumo. Nociones fundamentales, Tirant lo Blanch, Valencia, 2019, pp. 140 y siguientes. Sobre la posibilidad de aplicar la LPC a las prestaciones médicas o sanitarias, véase: BARRIENTOS, Francisca, "¿Cómo se insertan los servicios médicos en el ámbito de la Ley sobre protección de los derechos de los consumidores?", Revista de Ciencias Sociales, 2018, No 73, pp. 133-152
}

${ }^{6}$ Momberg, Rodrigo, "Definición de consumidores o usuarios" y "Definición de proveedores", en: De La Maza, I.; Pizarro, C. (Dir.), La protección de los derechos de los consumidores. Comentarios a la ley de protección de los consumidores, Editorial Thomson Reuters, Santiago, 2014, pp. 3-21; BarRIENTOS, Francisca, "La responsabilidad civil del fabricante bajo el artículo 23 de la ley de protección de los derechos de los consumidores y su relación con la responsabilidad civil del vendedor", Revista Chilena de Derecho Privado, 2010, №14, pp. 109-158; Mendoza, Pamela; Morales, María Elisa, "Notas sobre el control de cláusulas abusivas entre empresarios. una síntesis del modelo alemán", Revista Chilena de Derecho Privado, 2020, No 34. pp. 207-216.

${ }^{7}$ Véase Ley $\mathrm{N}^{\mathrm{o}} 20.416$, de 2010.

${ }^{8}$ Momberg, Rodrigo, "Derecho de Consumo: La empresa como consumidora: ámbito de aplicación de la LPC, nulidad de cláusulas abusivas y daño moral. Corte de Apelaciones de Talca, Rol No 674-2014 y Corte Suprema, Rol No 31-709-14", Revista de Derecho Privado, 2015, №25, pp. 279-287.

${ }^{9} \mathrm{Se}$ acoge, de este modo, el criterio positivo para la determinación del concepto de consumidor. Véase: Momberg, cit. (n. 6), p. 5; BaraOna, Jorge, "Concepto, autonomía y principios del derecho de consumo", en: Morales, M. (Dir.) Derecho del consumo: Ley, doctrina y jurisprudencia, DER Ediciones, Santiago, 2019, pp. 1-11.

${ }^{10}$ Se trataría de un comerciante de acuerdo con los artículos 3,7 y 8 del Cco. 
Los actos de consumo son aquellos señalados en la LPC (artículo 2). ${ }^{11}$ Dada su habitualidad y masificación, se suelen plasmar en contratos con cláusulas predispuestas y/o condiciones generales.

Este tipo de contratación surgió de las necesidades propias de la actividad económica actual, caracterizada por un alto volumen de transacciones y la rápida circulación de bienes y servicios. Esta modalidad, se concibe como una herramienta económica uniforme que disciplina la relación contractual en función de su rapidez e impacto en el crecimiento económico, se suscribe en serie y, por ende, su coste es el desplome de la libertad contractual, lo que ha obligado a repensar esta figura contractual. ${ }^{12}$

Recordemos que el contrato, en cuanto instrumento económico, sirve a la intermediación de bienes y servicios, lo que se logra por medio de un conjunto de cláusulas que prevén los distintos aspectos de esta relación. ${ }^{13}$ En general todo contrato debe confeccionarse tomando en consideración la ley aplicable, la que a su vez contendrá elementos imperativos (que no se pueden disponer por las partes) y dispositivos (donde la autonomía juega un rol central). En el primer elenco, encontramos aquellas cuestiones que ligan con las normas de orden público, tales como: la capacidad de las partes y los elementos esenciales del contrato; en el segundo, encontramos las modalidades que las partes asumen para el cumplimiento de las obligaciones, la determinación de un órgano competente para conocer de las controversias, así como otras de naturaleza accidental. La excepción a

\footnotetext{
${ }^{11}$ Momberg, Rodrigo, “Art. 2o”, en: De La Maza, I.; Pizarro, C. (Dirs.), La protección de los derechos de los consumidores. Comentarios a la ley de protección de los consumidores, Editorial Thomson Reuters, Santiago, 2014, pp. 66-75.

${ }^{12}$ En los Principios Unidroit sobre los contratos comerciales internacionales de 2016, se estipula en su artículo 2.1.19 (Contratación con cláusulas estándar) que: “(1) Las normas generales sobre formación del contrato se aplicarán cuando una o ambas partes utilicen cláusulas estándar, sujetas a lo dispuesto en los Artículos 2.1.20 al 2.1.22. (2) Cláusulas estándar son aquellas preparadas con antelación por una de las partes para su uso general y repetido y que son utilizadas, de hecho, sin negociación con la otra parte". Por su parte, el artículo 2.1.21 (Conflicto entre cláusulas estándar y no-estándar) dispone "En caso de conflicto entre una cláusula estándar $y$ una que no lo sea, prevalecerá esta última". UNIDROIT, Principios Unidroit sobre los contratos comerciales internacionales, 2016, https://www.unidroit.org/ spanish/principles/contracts/principles2016/principles2016-blackletter-s.pdf, consultada: 15 de junio de 2021.

${ }^{13} \mathrm{Si}$ bien las palabras cláusulas, condiciones, y estipulaciones contractuales se toman muchas veces como sinónimos, pues en general se refieren a las distintas partes que integran el contrato, debemos reparar en el hecho de que la cláusula es susceptible de ser entendida como una forma de división del contrato. En general nos encontraremos frente a una cláusula, cuando un supuesto de hecho se anuda a una consecuencia jurídica y, de este modo, es susceptible de un control específico.
} 
esta regla se encuentra en los contratos atípicos, es decir, aquellos que no se encuentran regulados normativamente.

Este diseño clásico, busca la interrelación de la autonomía de la voluntad junto a normas de orden público, que buscan resguardar aquellos elementos jurídicos esenciales que no se pueden soslayar sin que ello no provoque daño al funcionamiento del mercado (Ej. pérdida de confianza y seguridad). En otras palabras, las partes deben, en su esfera de libertad, negociar los contratos asumiendo ciertos riesgos, pero si esto no es posible, el Estado debe resguardar la validez de estos dispositivos.

Un contrato por adhesión es válido a menos que exista una causal de nulidad que le reste eficacia, lo que ocurre, por ejemplo, cuando su contenido atenta contra una norma indisponible o comporte un carácter abusivo en perjuicio del adherente, en desmedro del equilibrio entre los derechos y obligaciones de las partes. La protección del contratante débil justifica, entonces, la intervención del contrato por entidades estatales y jurisdiccionales, con atribuciones especiales destinadas a prevenir, remediar, interpretar o sancionar ciertas conductas. En base a ello, las legislaciones modernas han brindado al consumidor un sistema jurídico que lo ampara frente a conductas abusivas o dañinas provenientes de los proveedores. ${ }^{14}$

En Chile, a partir del año 1997, se dictó la LPC, que modera los principios clásicos de la contratación recogidos por el Código Civil (CC.) y Código de Comercio (Cco.), particularmente en lo concerniente a la formación del consentimiento y la fuerza obligatoria del contrato, la autonomía de la voluntad en el contenido y las consecuencias que envuelve el incumplimiento de deberes precontractuales y contractuales. ${ }^{15}$ Esta normativa distingue

\footnotetext{
${ }^{14}$ En este sentido: Martínez, Fernando, "La protección del asegurado en la jurisprudencia del Tribunal Supremo", en: Veiga, A. (Dir.), Martínez, M. (Coord.), Retos y Desafios del contrato de seguro: Del necesario aggiornamento a la metamorfosis del contrato. Libro homenaje al profesor Rubén Stiglitz, Cátedra Uría Menéndez - ICADE de Regulación de los Mercados. Parte III. Protección de consumidores, Editorial Thomson Reuters, Navarra, 2020, pp. 563-588; PERTínEz, Francisco, "Tutela de los consumidores y cláusulas abusivas en el contrato de seguro", en: Veiga, A. (Dir.), Martínez, M. (Coord.), Retos y Desafios del contrato de seguro: Del necesario aggiornamento a la metamorfosis del contrato. Libro homenaje al profesor Rubén Stiglitz, Cátedra Uría Menéndez - ICADE de Regulación de los Mercados. Parte III. Protección de consumidores, Editorial Thomson Reuters, Navarra, 2020, pp. 589-612.

${ }^{15}$ El Tribunal Constitucional, con fecha 13 de mayo de 2008, en la causa Rol No 980-07, señaló que el derecho del consumidor tiene una clara impronta social y protectora, cuya normativa se funda en la constatación de las desigualdades o asimetrías presentes en la relación de consumo entre una y otra parte, principalmente traducidas en su diferente nivel de información sobre los bienes o servicios a contratar, en su dispar capacidad negocial y en las distintas dificultades que enfrentan al momento de
} 
requisitos formales y de fondo en los contratos por adhesión. Los primeros, consisten en la escrituración del contrato o una referencia expresa a otro documento donde estén establecidas, y que se encuentre redactado en el idioma del país de que se trata, de forma legible y comprensible (artículo 17); los segundos, se refieren fundamentalmente a las cláusulas abusivas (artículo 16), lo que incardina con la necesidad de ejecutar los contratos de buena fe e interpretarlos en contra del redactor (artículos 1546 y 1566 del CC). También es posible advertir un conjunto de derechos del consumidor, tales como: la elección del bien o servicio (artículo 3 A), de información veraz y oportuna (artículo $3 \mathrm{~B}$ ), de no discriminación (artículo $3 \mathrm{C}$ ), de seguridad en el consumo (artículo 3 D), de reparación e indemnización (artículo $3 \mathrm{E}$ ), de retracto (artículo bis y ter), de irrenunciabilidad anticipada de derechos (artículo 4), etc. ${ }^{16}$

\subsection{El asegurado como consumidor}

El seguro, en cuanto a su objeto, es siempre un acto mercantil (artículo 3 $\mathrm{N}^{\circ} 9 \mathrm{Cco}$ ). Los sujetos, en cambio, pueden ser comerciantes o consumidores. La aseguradora es mercantil, atendido que se trata de una sociedad anónima especial (artículo $1^{\circ}$ Ley $\mathrm{N}^{\mathrm{o}} 18.046,1981$ ), y es considerada como un proveedor de servicios de consumo financiero por la LPC (artículo $17 \mathrm{~B}$ ); mientras que el asegurado o beneficiario podría ser un consumidor o un comerciante. De este modo, el acto o contrato de seguro podría ser mercantil o mixto. En la práctica, la mayor parte de los contratos de seguros tienen este último carácter y constituyen un producto financiero.

La importancia de esta distinción, radica en las leyes aplicables y el cruce que se genera entre aquellas, pues las reglas no se constriñen a las establecidas en el Cco., y sus leyes complementarias, sino que también

hacer efectivos sus respectivos derechos, por lo que el legislador se ha orientado por un predicamento tuitivo de los intereses de la parte más débil o desfavorecida de la relación jurídica, vale decir, el consumidor. Lo anterior implica un principio general de interpretación en favor del consumidor, conocido como pro-consumidor.

${ }^{16}$ A nivel internacional, esta realidad provocó la dictación de diferentes normativas reguladoras con ánimo de proteger al contratante débil, es decir, al adherente. Fue así como se dictó entre otras, la Directiva 13/93, de 1993, de la Comunidad Económica Europea. Estas tendencias legislativas y doctrinarias encuentran su origen en las reglas sobre formación del contrato contenidas en la Convención de las Naciones Unidas sobre Compraventa Internacional de Mercaderías, adoptada en Viena en 1980 y elaborada en el seno de la Comisión de las Naciones Unidas para el Derecho Mercantil Internacional (suscrita en Chile en 1990). 
alcanzan a las de carácter supletorio (artículo $2^{\circ}$ Cco.), y las contenidas en la LPC, en cuanto norma especial. ${ }^{17}$ En caso que se genere un concurso de normas, debemos considerar que no puede regir el clásico principio comercial que supera este problema por medio de la ley del obligado, sino que deberemos atender a la ley que resulta más beneficiosa para el asegurado si este es consumidor, ${ }^{18}$ en atención al principio pro-consumidor imperante en la materia.

El asegurado y el consumidor son sujetos distintos y sus estatutos jurídicos se articulan sobre aquellos, de manera que la aplicación de sus normativas, no siempre serán convergentes. El término asegurado es más amplio que el de consumidor, pero en general resulta indiscutido que este último queda comprendido en el concepto de asegurado. El criterio se debiese articular sobre el principio de prioridad valorativa de la tutela del consumidor, en otras palabras, la norma más beneficiosa para el aseguradoconsumidor. En esta senda, se extraña una declaración expresa del legislador en tal sentido. ${ }^{19}$

El hecho que el asegurado sea normalmente un consumidor fue una de las razones que motivó, tanto en derecho comparado ${ }^{20}$ como en Chile, la inserción de ciertos mecanismos de protección en favor de aquél. ${ }^{21} \mathrm{La}$ reforma, sin embargo, no alude al asegurado o beneficiario como consumidor

\footnotetext{
${ }^{17}$ Se ha discutido si el artículo 2 bis LPC excluye la aplicación de las materias reguladas por leyes especiales. Antes del nuevo estatuto de seguros, era más fácil plantear la aplicabilidad de la LPC al seguro, pues el Cco., no tenía por objeto resguardar al asegurado-beneficiario, hoy en día se agrega a la discusión la circunstancia de que tenemos dos estatutos protectores eventualmente confrontados. En nuestra opinión, aquí debe tenerse presente que lo regulado en ambos estatutos son, en general, cuestiones diversas, y en último caso, siendo ambas normas protectoras e imperativas (o irrenunciables) debiese entenderse que operan en conjunto y en caso de cruce, la que resulte más favorable al asegurado.

${ }^{18} \mathrm{El}$ artículo $2^{\circ}$ bis LPC se ha interpretado de una manera confusa y contradictoria, lo que seguramente se debe a una defectuosa técnica legislativa. En este sentido: MomBerg, Rodrigo, "Leyes especiales y aplicación de la ley 19.496 sobre protección de los derechos de los consumidores. Análisis de casos", en: Morales, M., (Dir.) Derecho del consumo: Ley, doctrina y jurisprudencia, DER Ediciones, Santiago, 2019, pp. 25-45.

${ }^{19}$ En este sentido: Bataller, Juan, "Una mejor protección del asegurado es posible”, en: Girgado, P. (Dir.), El contrato de seguro y su distribución en la encrucijada, Editorial Aranzadi, Navarra, 2018, pp. 347-375.

${ }^{20}$ En España se dictó la Ley N${ }^{\circ}$ 0, de 1980; en Francia la Ley de Seguro, 1930 y luego un Código de Seguros; en Alemania se dictó una nueva Ley sobre Contrato de Seguro, 2007; y nuestro país recogió esta tendencia en 2013 con la Ley N 20.667, de 2013.

${ }^{21}$ Antes de ello, los contratantes eran vistos en igualdad de condiciones e inclusive se proporcionaban normas más ventajosas para el asegurador, al considerarse que la información de los riesgos era manejada por el asegurado.
} 
de manera expresa, ni menciona este vocablo en alguna de sus disposiciones, sin embargo, ello no representa un problema mayor si consideramos que la LPC se integra al estatuto jurídico protector del asegurado que revista tal calidad, lo que ocurrirá cuando se presenten las calificaciones jurídicas requeridas por dicha ley para su aplicación, esto es, la existencia de un acto de consumo, un consumidor y un proveedor. ${ }^{22}$ En esta dirección, se incorporan resguardos a fin de que la aseguradora asuma ciertas cargas y obligaciones. ${ }^{23}$ En general, destacan tres mecanismos de protección, a saber: la imperatividad de las normas legales que rigen al contrato de seguro, la redacción de la póliza bajo ciertos requisitos, y una acción procesal para reclamar incumplimientos contractuales. Veremos a continuación cada uno de ellos.

\section{PRIMER MECANISMO DE PROTECCIÓN: IMPERATIVIDAD NORMATIVA}

\subsection{Delimitación del principio de imperatividad: ¿Qué hay de nuevo?}

Una de las reformas más relevantes que introdujo la Ley No 20.667, de 2013 fue el principio de imperatividad. ${ }^{24}$ Se trata de una declaración general en orden a establecer que las normas que rigen al seguro no pueden ser modificadas por las partes. ${ }^{25}$ Antes de aquella, las normas con este carácter eran menores y se vinculaban a materias tales como: los elementos

\footnotetext{
${ }^{22}$ Contreras, Osvaldo. Derecho de Seguros, Editorial Thomson Reuters, La Ley, Santiago, 2014, $2^{\circ}$ edición, pp. 717-722.

${ }^{23}$ Enunciando este principio: JARA, Rony, “Ámbito de aplicación de la ley chilena de protección al consumidor inclusiones y exclusiones", en: CoRRAL, H. (Ed.) Derecho del consumo y protección al consumidor Estudios sobre la Ley $N^{\circ} 19.496$ y las principales tendencias extranjeras. Cuadernos de Extensión Jurídica, Ediciones Universidad de los Andes, Santiago, 1999, № 3, pp. 47-74.

${ }^{24}$ También podemos añadir el artículo $529 \mathrm{del} \mathrm{Cco.} \mathrm{(deber} \mathrm{precontractual} \mathrm{de} \mathrm{asesoría} \mathrm{al} \mathrm{asegurado)} \mathrm{y}$ los artículos 514 y 517.

${ }^{25}$ El legislador chileno estableció la regla de imperatividad imitando a la Ley francesa de 1930 y a la española de 1980, que fueron referentes en la construcción de la reforma chilena. Estas normativas en cita se adelantaron a las Directivas Europeas en materia de protección al consumidor, que a su vez se inspiran en los Principios Europeos del Derecho de los contratos (PECL), 2002, que en su artículo 1102 dispone: "Las partes son libres de celebrar un contrato y para determinar el contenido del mismo, siempre que se observen las exigencias de la buena fe y de la lealtad y las reglas imperativas de estos principios".
} 
esenciales del contrato, su nulidad y prescripción. Tal regulación no estaba pensada en la protección de un contratante débil, toda vez que partía del supuesto de libre contratación, ampliamente superado en la práctica por los contratos por adhesión. ${ }^{26}$ En tal sentido, la imperatividad fue pensada como un límite a la autonomía de la voluntad, a fin de fijar un piso legal mínimo protector del adherente. ${ }^{27}$

Frente a este nuevo paradigma, surgieron múltiples interrogantes: ¿Todas las normas de seguro se entienden imperativas?, ¿Todas las normas imperativas del contrato de seguro se establecen en favor del asegurado?, ¿Cómo opera esta limitación en la práctica?, ¿Cuál sería la consecuencia ante una posible infracción? y, lo más importante, ¿Es eficiente esta imperatividad?

Como punto de partida, es necesario señalar que si bien el artículo 542 establece la imperatividad como regla general, dispone como excepción aquellos casos en que las estipulaciones contractuales sean más beneficiosas para el asegurado o el beneficiario, prevención que no regirá en los seguros de transporte marítimo, aéreo, casco y de daños contratados individualmente que cumplan con los requisitos establecidos en la norma (que el beneficiario o asegurado sea una persona jurídica; que el monto de la prima anual no sea inferior a $200 \mathrm{UF}) .^{28}$

La imperatividad es un avance para el asegurado, primero, porque en materia de protección al consumidor no se contempla esta regla de manera expresa, más bien su tratamiento dogmático se ha desarrollado a partir de un ejercicio hermenéutico derivado del artículo $4^{\circ} \mathrm{LPC}$; y segundo, porque antes de esta modificación, el juez tenía que verificar casuísticamente si la

\footnotetext{
${ }^{26}$ A modo ejemplar, citamos la sentencia pronunciada por la Corte Suprema, 24 de junio de 2011, Rol $\mathrm{N}^{\mathrm{o}}$ 6297-2009, que dispuso: "El contrato de seguro y los derechos y obligaciones que dé el provienen son regidos, en primer lugar, por las normas y cláusulas que las propias partes hayan convenido en el contrato respectivo. Se aplica en su integridad, a este respecto, el principio de libertad contractual consagrado en el Art. 1545 del código civil (...) A falta de estipulación expresa por las partes y en forma supletoria, se aplican, en primer lugar, las normas especiales que regulan el respectivo contrato de seguro (...)".

${ }^{27}$ En la discusión del proyecto de ley, el catedrático Osvaldo Contreras señaló que la obligatoriedad de estas leyes protectoras del asegurado encuentra su justificación en la calificación del tomador del seguro como un contratante débil, entendiendo esta debilidad en el sentido económico y de conocimiento técnico. Véase en: Biblioteca del Congreso Nacional de Chile, Historia de la Ley N²0.667, 2018, pp. 69 y ss.

${ }^{28}$ En esta parte, se sigue la legislación española, de tal manera que se exceptúa de la imperatividad a los seguros de "grandes riesgos". Véase en: Biblioteca del Congreso Nacional de Chile, Historia de la Ley $N^{\circ} 20.667,2018$, p. 3.
} 
norma gozaba de imperatividad, lo que se prestaba para cierta confusión. ${ }^{29}$ Quizá por ello, la doctrina se ha centrado básicamente en exacerbar estas virtudes y analizar las exclusiones indicadas en el precepto en comento, sin perjuicio que muchos de los seguros allí enunciados también requieren de esta protección. ${ }^{30}$

La doctrina chilena ha discurrido sobre sus fundamentos y efectos, pero no ha abordado suficientemente la eficacia de este mecanismo. En esta línea, CONTRERAs señala que la imperatividad tuvo por objeto otorgar una protección a los asegurados en los seguros que no sean de grandes riesgos, fundado en el hecho que el contrato es por adhesión. ${ }^{31}$ Ríos por su parte, advierte que es esta falta de equilibrio o asimetría contractual, la que justifica el establecimiento de la norma en comento, de manera que la imperatividad impide a los contratantes establecer una regla diferente a lo normado, con el fin de tutelar al asegurado. ${ }^{32}$ BARRIENTos sostiene que se trata de una norma que mira básicamente a la validez del contrato de seguro y su vulneración tiene como consecuencia que la nulidad sobre requisitos esenciales del contrato (artículo 521 Cco.) sólo puede ser intentada por el asegurado, tomador o beneficiario del seguro;33 mientras Ruiz TAGLE, en el mismo derrotero, indica que la imperatividad se expresa en los contratos de seguro de forma que las cláusulas de la generalidad de los contratos resultan inmodificables para las partes. ${ }^{34}$

De este modo, existe consenso en los siguientes hechos: a. Que la imperatividad constituye una innovación de la Ley $\mathrm{N}^{\mathrm{o}} 20.667$ siguiendo las tendencias de derecho comparado, en especial, España; b. Que la

${ }^{29}$ En este sentido: Contreras, Osvaldo, El contrato de seguro, La Ley, Santiago, 2002, $1^{\circ}$ edición, pp. 21-22; Lagos, Osvaldo, "La reforma al derecho del contrato de seguros", Revista Chilena de Derecho de Seguros, 2014, pp. 27-57.

${ }^{30}$ Véase: Contreras, cit. (n. 22), p. 41-58; Ríos, Roberto, "Comentarios Art. 542 del Cco", en: Ríos, R., (Dir.) El Contrato de Seguro Comentarios al Título VIII, Libro II del Código de Comercio, Thomson Reuters, Santiago, 2015.

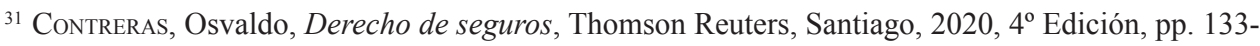
134.

${ }^{32}$ Ríos, cit. (n. 30), p. 465. También en: Ríos, Roberto, "La imperatividad en la regulación del contrato de seguro", Revista Española de Seguros, 2019, № 178, pp. 185-205.

${ }^{33}$ BARrientos, Marcelo, "La unilateral imperatividad de los requisitos esenciales del contrato de seguro en el código de comercio chileno", Rev. Bol. de Derecho, 2016, No 22, pp. 98-119.

${ }^{34}$ Ruz Tagle, Carlos, "La imperatividad como nuevo desafío de la institucionalidad del seguro chilena", Revista Chilena de Derecho de Seguros, 2015, № 24, pp. 67-84. 
imperatividad que se recoge es de corte general, ${ }^{35}$ de manera que debemos interpretar qué entendemos por normas imperativas que rigen el contrato de seguro, ${ }^{36}$ integrando otros preceptos; c. Que esto se debe al reconocimiento de que el contrato de seguro no es de libre negociación, por regla general, sino por adhesión; d. Que esta herramienta busca proteger al contratante débil de la relación contractual; y e. Que, si bien no se señala expresamente la sanción, debiésemos entender que se trata de la nulidad de la cláusula en cuestión.

\section{2. Ámbito de aplicación material de la imperatividad}

El artículo 542 Cco. no se refiere a un catálogo de materias o disposiciones que resultan imperativas, sólo hace referencia a un enunciado general. De lo anterior, se coligen tres cuestiones relevantes: Primero, que las normas que rigen el contrato de seguro son -por regla generalimperativas; Segundo, esta imperatividad debe respetarse en abstracto, esto

\footnotetext{
${ }^{35}$ Nuestra normativa no distingue qué normas deben entenderse como imperativas, a diferencia de otras legislaciones que diseccionan expresamente este punto. Detallando las normas calificadas como imperativas, podemos encontrar la ley francesa, de 1930 en su artículo 1.111-3 del Code des Assurances; Argentina, que en su artículo 158 de la Ley No 17.418, 1967 sigue el criterio de selección de algunos artículos que se presentan como inmodificables; y la Ley $\mathrm{N}^{\circ} 389,1997$ colombiana que tiene un sistema de mayor flexibilidad en que se pueden encontrar preceptos inmodificables y otros que pueden modificarse siempre que sean favorables al tomador, asegurado o beneficiario. Siguiendo un criterio general, podemos observar el derecho español, cuyo artículo $2^{\circ}$ de la ley de seguros, indica: "Las distintas modalidades del contrato de seguro, en defecto de Ley que les sea aplicable, se regirán por la presente Ley, cuyos preceptos tienen carácter imperativo, a no ser que en ellos se disponga otra cosa. No obstante, se entenderán válidas las cláusulas contractuales que sean más beneficiosas para el asegurado". En cuanto a la sanción por una transgresión de la imperatividad en la ley española, declarada por el Tribunal Supremo la nulidad de alguna de las cláusulas de las condiciones generales de un contrato la Administración Pública competente, obligará a los aseguradores a modificar las cláusulas idénticas contenidas en sus pólizas. En ningún caso podrán tener carácter lesivo para los de la Ley 50/80 sobre contratación de seguros. José Miguel Embid explica que el hecho de que las normas de seguro tengan, por regla general, naturaleza imperativa implica necesariamente la nulidad de las cláusulas contractuales que se le opongan a ello, manteniéndose la validez del contrato en el que se insertan. Embid, José, "Preliminar", en: Boquera, J., Ballater, J., Olavarría, J., (Coords.), Comentarios a la ley de contratos de seguros, Tirant lo Blanch, Valencia, 2002, p. 65.

${ }^{36}$ Esto nos obliga a pensar que las normas que regulan el contrato de seguro no se encuentran sólo insertas en el Cco., sino que este marco jurídico también se integra por las normas de la LPC, y las normas complementarias del seguro, como es el DFL N 251 , 1931 y las Normas de Carácter General (NCG) que dicta la Comisión para el Mercado Financiero (CMF) En esta línea, véase: RuBio, Francisco, "Elementos para la armonización de la legislación de seguros y de consumo en la protección del consumidor de seguros", Revista de Derecho y Consumo (Fundación Fernando Fueyo), 2019, №3 pp. 9-49.
} 
es, sin considerar si afecta o no a los asegurados; ${ }^{37}$ y Tercero, en la expresión "disposiciones que rigen el contrato" a nuestro parecer, nos lleva a incluir no sólo las normas contenidas en el Cco., sino también las complementarias y supletorias, pues no existe una distinción o prevención sobre el particular. ${ }^{38}$

Entre los preceptos que debemos considerar, encontramos los relativos a la formación del consentimiento (artículos. 97 y siguientes del Cco.), los referidos a la capacidad y representación, los que establecen requisitos esenciales del contrato de seguro, los que consignan deberes, obligaciones y efectos contractuales indisponibles, los referentes a causales de ineficacia del contrato y los de prescripción y solución de conflictos. ${ }^{39}$ A ello sumamos el elenco de normas que consagran los derechos de los consumidores. Desde esta óptica, estimamos que la imperatividad no sólo se propone como una garantía para la validez del contrato, ${ }^{40}$ sino que también como una medida general de protección del asegurado.

El mandato de imperatividad busca resguardar ex ante y ex post al asegurado. En el primer caso, se exige a la aseguradora elaborar la respectiva póliza de seguro sin prescindir de las normas a que hemos hecho alusión, a menos que se establezcan cláusulas que resulten más beneficiosas para el asegurado o se den los presupuestos de excepción. En esta dirección, el asegurador debe redactar la póliza distinguiendo las condiciones generales de las particulares. Adicionalmente, debe dar cumplimiento a lo dispuesto en el DFL N 251 y la Norma de Carácter General (NCG) No $349^{41}$ y depositar la póliza en la Comisión para el Mercado Financiero (CMF). En el segundo caso, la revisión puede ser efectuada por el juez o árbitro que resuelve un determinado conflicto sobre esta materia.

La normativa no señala una sanción especial frente a la vulneración de la imperatividad, de manera que debemos entender que esta será la nulidad. ${ }^{42}$

\footnotetext{
${ }^{37}$ Eventualmente podría operar en perjuicio de mejores negociaciones. IsLER, cit. (n. 5), p. 97 y siguientes.

${ }^{38}$ En esta línea, podemos encontrar todas aquellas normas sobre derechos y obligaciones que se consideran indisponibles en el Cco., DFL N²51, 1931, NCG N³49, 2011, y Ley Nº 19.496, 1997.

${ }^{39}$ Contreras, cit. (n. 22), p. 125.

${ }^{40}$ BARRIENTOS, cit. (n. 33), pp. 98-118.

${ }^{41}$ En este mismo sentido: Ríos, cit, (n. 30), p. 468.

${ }^{42}$ Sobre las consecuencias jurídicas de esta norma: Ríos, Roberto, "La imperatividad de las normas que regulan el contrato de seguro en el ordenamiento jurídico chileno y el control de contenido del contrato: ¿Cambio radical en el sistema de aseguramiento?”, en: Jequier, E., (Coord.), Estudios de Derecho Comercial, Cuartas Jornadas Chilenas de Derecho Comercial, Legal Publishing, Thomson
} 
A ello podríamos añadir, la prohibición de utilizar la póliza en cuestión si ello es determinado por la CMF. No huelga señalar, que estas consecuencias no podrían ser renunciadas por los asegurados anticipadamente, pues ello contravendría normas de orden público.

La sanción de nulidad no resulta discutida por la doctrina, sin embargo, parece claro que si se trata de la defensa o protección del contratante débil, no parece la más adecuada de las soluciones. Recordemos que la sanción de nulidad en el contrato de seguro se anuda a contadas hipótesis, como son: la vulneración de los elementos esenciales del contrato (artículo $521 \mathrm{Cco}$.); el suministro de información falsa a sabiendas por parte del tomador o asegurado (artículo $539 \mathrm{Cco}$.); o por reticencias, inexactitud o falsedad de la información que se juzgue relevante para determinar la extensión del riesgo (artículo 1176 Cco.). Cada uno de estos supuestos liga con un elemento de la esencia del contrato, por lo que la sanción resulta atingente. En el caso del artículo 542 esto no tiene la misma lógica, pues aquí se señala una cuestión más amplia en la medida que se declara, de manera general, que las normas del contrato de seguro deben entenderse "imperativas". Si la normativa sobre seguro sólo se refiriese a los elementos esenciales o de resguardo del asegurado, ello sería pertinente, sin embargo, esta calificación resulta mucho más extensa y no siempre se resguarda los intereses del contratante débil. En otras palabras, no existe simetría ni concordancia entre la regulación de este contrato y el artículo 542, de manera que este mecanismo de tutela resulta inconcuso y hasta forzado.

Por otra parte, la sanción en sí misma no es beneficiosa, pues si el contrato de seguro resulta nulo en su integridad, el asegurado tendrá que suscribir un nuevo seguro, el que podría resultar más oneroso si existe una variación de circunstancias (por ejemplo, si se le ha diagnosticado una nueva enfermedad). Incluso, su posición económica podría verse mermada

Reuters, Santiago, 2014, pp. 49-51; Ríos, cit. (n. 30), p. 468 y ss. Toso, por su parte, subraya el hecho de que podría generarse alguna confusión sobre cómo coordinar el carácter imperativo de las normas del contrato de seguro de transporte terrestre, en aquellos supuestos en que deba aplicarse la regulación del seguro marítimo, que da un amplio espacio a la autonomía de la voluntad (artículo $1159 \mathrm{Cco}$ ). Sin embargo, este escenario no se presentará con frecuencia, ya que las normas referidas específicamente al contrato de seguro de transporte terrestre en el Cco (artículos 575 a 577) ya dan un amplio espacio a la voluntad de las partes. Toso, Ángela, "Comentario al artículo 577 del Cco", en: Ríos, R., (Dir), El Contrato de Seguro Comentarios al Título VIII, Libro II del Código de Comercio, Thomson Reuters, Santiago, 2015, p. 684. En igual sentido Contreras, quien señala que esta es una excepción. CONTRERAs, cit. (n. 22), p. 505. 
con esta medida, a diferencia de la aseguradora, que no tendrá ningún efecto pernicioso, pues no se le sanciona por medio de multas o una indemnización de perjuicio en favor del asegurado. Una forma de corregir lo anterior, sería interpretar la norma diseccionando aquellas cláusulas que son ambiguas de las que resultan ilegales por vulnerar normas imperativas y, en este último caso, entender que la nulidad sólo debe afectar a la cláusula contractual en cuestión. En ambos casos, la revisión administrativa y/o judicial sería necesaria pero el resultado de esta labor. En consecuencia, las cláusulas ambiguas, no debieran anularse sino sólo interpretarse en beneficio del asegurado; mientras que las cláusulas ilegales, podrían dar lugar a una nulidad o ineficacia parcial, ${ }^{43}$ esto es, sólo afectar la parte que contraría la normativa, ejercicio que puede entenderse justificado por el principio de separación contractual y pro consumidor. Lo que se ha declarado nulo o ineficaz debiese sustituirse por lo señalado en las normas quebrantadas, integrando el contrato con estas disposiciones en defensa del asegurado. ${ }^{44}$ Si así se resuelve, el asegurado podrá seguir gozando de los derechos que le confiere el contrato, pues en lo demás seguirá siendo válido. ${ }^{45} \mathrm{Si}$ se llegase a declarar la nulidad del contrato por no ser posible lo anterior, la aseguradora debiera ser obligada a reparar al asegurado por medio de la suscripción de un nuevo contrato en las mismas o mejores condiciones e indemnizando los perjuicios que esto le ha provocado, entendiendo la vulneración a la imperatividad como un incumplimiento contractual de la aseguradora.

Desde otra perspectiva, observamos que las normas imperativas que rigen al contrato de seguro en el Cco., no siempre miran en interés del

\footnotetext{
${ }^{43}$ Debemos hacer presente que el principio de separabilidad de las cláusulas contractuales tiene sus orígenes en el derecho comercial internacional (depacage), que busca la conservación de la relación contractual y económica entre las partes. A modo de ejemplo, un contrato arbitral puede adoptar la forma de cláusula en otro contrato, de manera que, si se alega la nulidad de este último, el árbitro podría revisar esta materia (competence-competence) sin afectar el contenido de las restantes cláusulas contractuales.

${ }^{44}$ Esto operaría de una manera análoga a lo dispuesto en el artículo $17 \mathrm{E}$ de la LPC inciso $1^{\circ}$, que dispone: "Esta nulidad podrá declararse por el juez en caso de que el contrato pueda subsistir con las restantes cláusulas o, en su defecto, el juez podrá ordenar la adecuación de las cláusulas correspondientes, sin perjuicio de la indemnización que pudiere determinar a favor del consumidor". Con todo, no podríamos pensar que la LPC suple el vacío del artículo 542 del Cco, porque el ámbito de aplicación de esta norma es otro y no alcanza a todas las situaciones que podrían ocurrir.

${ }^{45}$ Sobre esta materia véase: BARRIEntos, Francisca, "Repensando el control de forma de los contratos por adhesión: una mirada a su aplicación actual y la introducción de la transparencia", en: BAHAMONDES, C., Etcheberry, L., Pizarro, C., (Eds.), Estudios de Derecho Civil XIII, Thomson Reuters, Santiago, 2018, pp. 1001-1018.
} 
asegurado, lo que nos fuerza a reflexionar nuevamente sobre la eficacia de esta norma en cuanto mecanismo protector. Así, por ejemplo, el artículo 525 Cco., sostiene que si el siniestro se ha producido y el contratante hubiere incurrido en errores, reticencias o inexactitudes en la información que solicite el asegurador sobre el riesgo, éste podrá rescindir el contrato y no pagar la prestación convenida. Nótese que esta norma no exige dolo, sino sólo un incumplimiento imperfecto de un deber del asegurado en orden a declarar las circunstancias del riesgo. ${ }^{46}$ Otro tanto ocurre con lo planteado en el artículo 519 inciso final del Cco., al establecer que frente a la falta de entrega de la póliza por parte del asegurador ( 5 días desde la perfección del contrato) este incumplimiento dará "derecho" al asegurado a reclamar daños y perjuicios si esto se ha provocado. Lo mismo podríamos plantear respecto del artículo 543 del Cco., precepto que establece que los conflictos que se susciten a partir del contrato de seguro deberán ser resueltos por un juez árbitro, de manera que se inhibe al asegurado de acudir al juez natural (justicia estatal), vulnerando con ello un derecho constitucional, ${ }^{47} \mathrm{y}$ la voluntariedad que debiese primar en el arbitraje. ${ }^{48}$ En suma, el problema de fondo que aquí vislumbramos es que no todas las normas imperativas que rigen a este contrato son favorables al asegurado, de manera que su cumplimiento en nada les puede beneficiar. Desde este ángulo, revisar este mecanismo de protección resulta muy necesario en cuanto a las reformas normativas.

Desde otra perspectiva, el DFL N 251 y la NCG N 349 colaboran en esta definición. El artículo $3^{\circ}$ letra e) del DFL en referencia dispone que será atribución y obligación de la Superintendencia (hoy CMF), ${ }^{49}$ mantener

\footnotetext{
${ }^{46}$ De hecho, a diferencia de lo que ocurre con las normas que sirvieron de antecedente a la Ley $\mathrm{N}^{\circ}$ 20.667 (Ej. artículo 10 de la Ley 50/1980 española), no se plantea una causal consistente para atribuir este efecto. Tampoco se confiere un plazo, ni se verifica cuándo tomó conocimiento de estos errores, de manera que podría ocurrir que reciba la prima durante largos años, y sólo cuando se produzca el siniestro alegue esta circunstancia.

${ }^{47}$ VÁsquez, María Fernanda, Tratado de arbitraje en Chile, Thomson Reuters, Santiago, 2018, pp. 15 y 476 .

${ }^{48}$ El Tribunal Constitucional Español, el 11 de enero de 2018, en la causa Rol No $1 / 18$ declaró que el artículo 76 e) Ley de Seguro $N^{\circ} 1957,1980$ ) vulnera el derecho fundamental a la tutela judicial efectiva del asegurador, en relación con el principio de exclusividad jurisdiccional establecido por el artículo 117.3 CE. Se afirma, asimismo, que es contraria al artículo 117.3 CE (Ley N²500, de 1978) la atribución a una de las partes de la facultad unilateral de someter la cuestión litigiosa a arbitraje, en cuanto supone una renuncia a la jurisdicción y conlleva la exclusión de la vía judicial.

${ }^{49}$ Con la Ley N ${ }^{\circ} 21.000,2017$, se crea la Comisión para el Mercado Financiero (CMF) que reemplaza
} 
a disposición del público los modelos de textos de condiciones generales de pólizas y cláusulas que se contraten en el mercado. Las entidades aseguradoras podrán contratar con dichos modelos a partir del sexto día que hubieren sido incorporados al Depósito de Pólizas que, para esos efectos, llevará la Superintendencia. ${ }^{50}$ Será responsabilidad de las compañías que las pólizas de seguros que contraten estén redactadas en forma clara y entendible, que no sean inductivas a error y que no contengan cláusulas que se opongan a la ley. En caso de duda sobre el sentido de una disposición en el modelo de condición general de póliza o cláusula, prevalecerá la interpretación más favorable para el contratante, asegurado o beneficiario del seguro, según sea el caso.

\subsection{Delimitación negativa: excepciones que se plantean respecto de la imperatividad}

A. Estipulaciones contractuales más beneficiosas para el asegurado o beneficiario

De acuerdo al artículo 542 las normas imperativas ceden en favor de las estipulaciones más beneficiosas para el asegurado o beneficiario. ${ }^{51} \mathrm{En}$ nuestra opinión, la consagración de este principio resulta tan importante como la imperatividad en sí misma, toda vez que el principio "favor consumatore" no se consigna de manera expresa en la LPC y sólo es posible extraerlo del CC., a partir del artículo $1566 .{ }^{52}$ Empero, no resulta claro cuándo estaremos

\footnotetext{
a la Superintendencia de Valores y Seguros (SVS).

${ }^{50}$ En concordancia con el artículo 542 Cco, este precepto señala: "Las compañías de seguros del primer grupo, en los casos de seguros de Transporte y de Casco Marítimo y Aéreo, como asimismo en los contratos de seguros en los cuales, tanto el asegurado como el beneficiario, sean personas jurídicas y el monto de la prima anual que se convenga no sea inferior a 200 unidades de fomento, no tendrán la obligación señalada en el párrafo precedente, y podrán contratar con modelos no depositados en la Superintendencia, debiendo la póliza respectiva ser firmada por los contratantes".

${ }^{51}$ En España, la declaración de que serán válidas las cláusulas contractuales que sean más beneficiosas para el asegurado, se encuentra presente en la letra b) del artículo 581-2 ACM, como lo está en el artículo 2 Ley 50/180. Ejemplos de ello podemos encontrarlos dentro del propio anteproyecto del código de comercio, en el artículo 582-44.2, que establece que son válidas las cláusulas que amplíen los plazos legales de extensión temporal de la cobertura el asegurador de la responsabilidad civil; y en el artículo 583-12, que permite fijar en la póliza un término más breve que el marcado en él para la impugnación por el asegurador del contrato de seguro de personas en caso de reticencia o inexactitud del tomador en la declaración del riesgo.

${ }^{52}$ Esta norma señala: "No pudiendo aplicarse ninguna de las reglas precedentes de interpretación, se interpretarán las cláusulas ambiguas a favor del deudor. Pero las cláusulas ambiguas que hayan sido
} 
en presencia de estas estipulaciones y a quién le corresponderá determinarlo.

La expresión "estipulaciones" debemos entenderla en un sentido amplio, toda vez que puede tratarse incluso de una cláusula contractual redactada en favor del asegurado que le otorga una determinada opción, derecho o beneficio, con la limitación del respeto a cuestiones esenciales del contrato. En la misma línea, podríamos considerar que existe un derecho a opción del asegurado en orden a elegir aquello que le parezca más beneficioso, pudiendo sólo él reclamarlo. En tal sentido, podríamos entender que aquél puede renunciar a la justicia arbitral establecida en el artículo 543 del Cco., para acudir a los caminos judiciales propios del consumidor. ${ }^{53}$ Finalmente, la norma imperativa interpretada en beneficio del asegurado no deja de tener este carácter en relación al asegurador, de manera que en tal caso la imperatividad asume cierta unilateralidad.

B. Los seguros de daños contratados individualmente, entre personas jurídicas cuya prima sea superior a 200 U.F., los de casco y de transporte aéreo o marítimo. ${ }^{54}$

El legislador chileno, a diferencia de las legislaciones que le sirvieron de antecedente, no plantea como excepción el seguro de grandes riesgos, ${ }^{55} \mathrm{sin}$

extendidas o dictadas por una de las partes, sea acreedora o deudora, se interpretarán contra ella, siempre que la ambigüedad provenga de la falta de una explicación que haya debido darse por ella".

${ }^{53} \mathrm{El}$ anteproyecto del Cco., de 2010 de España, tuvo una refacción diferente en 2011 en relación a las normas de consumo aplicables al contrato de seguro, pues mientras que en los dos primeros textos la aplicación de la legislación protectora de los consumidores era meramente supletoria, luego se intercala la expresión "sin perjuicio de", de manera que las normas del Código Mercantil no pueden reducir el nivel de protección o interferir en la aplicación de las normas de defensa de los consumidores. Más tuitiva y adecuada para la necesaria protección de tomador y asegurado, que normalmente se aperciben de la discrepancia en el momento del siniestro, cuando ya puede haber transcurrido con creces el plazo legal de prescripción, nos parece el Art. 2:502 de los Principios del Derecho Europeo de Contrato de Seguro (PDECS), porque obliga al asegurador a resaltar la divergencia y supedita su vigencia y efecto a la falta de rechazo por el tomador en el plazo de un mes, que aquí sí tiene sentido, puesto que previamente se ha alertado al tomador, por medio de su resalte (que se impone de forma expresa que ha de ser "con letra negrita"), sobre la existencia de diferencias, el contenido de éstas y su derecho a rechazarlas. Morillas, María José, "Las normas sobre el contrato del seguro como ley general imperativa: Límites y excepciones, en particular, la referida a los seguros de grandes riesgos. Una aproximación al Art. 581-2 del anteproyecto código mercantil”, en: Morillas, M., Perales, M., Porfirio, L., (Dirs.), Estudios sobre el futuro Código Mercantil: libro homenaje al profesor Rafael Illescas Ortiz, Universidad Carlos III de Madrid, 2015, pp. 1556-1590.

${ }^{54}$ Sobre el art. 542, destaca el análisis pormenorizado de: LARRAín, Carlos, "Sentido y alcance del principio de imperatividad de las normas legales relativas al contrato de seguro", Revista Chilena de Derecho de Seguros, 2015, № 24, pp. 219-221.

${ }^{55}$ No existe un concepto unívoco sobre esta noción. Así, por ejemplo, el artículo 7.2 Reglamento Roma 
embargo, es frecuente que la doctrina erradamente se refiera a tal excepción bajo tal denominación. ${ }^{56}$ Consideramos que la excepción en comento no se encuentra bien redactada, pues si se pretendía dejar fuera a los seguros que no afectaran a los consumidores, el objetivo no se logra con esta formulación, ya que es perfectamente posible que consumidores como las pequeñas y medianas empresas, celebren un contrato con una prima mayor a la señalada (200 U.F.), quedando fuera del ámbito de protección de la referida norma. En virtud de ello, y mientras el precepto no sea reformado, resulta necesario reinterpretarlo, atendiendo el criterio pro consumatore que, en estricto rigor, era la intención legislativa.

\section{SEGUNDO MECANISMO DE PROTECCIÓN: CONTENIDO Y CONTROL DEL CONTRATO DE SEGURO}

El contrato de seguro, por su parte, representa uno de los principales instrumentos económicos, sociales y jurídicos que ha permitido, facilitado y desarrollado las relaciones negociales en esta materia. Como correlato de ello, la actividad aseguradora es en la actualidad uno de los mercados más atractivos desde el punto de vista económico. Como señalamos, el contrato de seguro o póliza admite dos formatos: de libre negociación y por adhesión. Este último es el más utilizado en la práctica, y la reforma de 2013 puso especial atención en ello.

Como señala VeIGA, quien contrata un seguro en cierto modo, anticipa y traslada la posibilidad del riesgo en base a una necesidad de garantía y seguridad. Ponderar los riesgos, calibrarlos, mesurarlos, debiese responder a un principio de proporcionalidad, de equilibrio, de equidad entre las partes. ${ }^{57}$ En la búsqueda de este equilibrio sinalagmático se ha de tener y

\footnotetext{
I, 2008 que, en lugar de proporcionar un concepto de grandes riesgos o el detalle de los mismos, efectúa una nueva remisión, esta vez al artículo $5^{\circ}$, d) de la Primera Directiva 73/239/CEE del Consejo, 1973, sobre coordinación de las disposiciones legales, reglamentarias y administrativas relativas al acceso a la actividad del seguro directo distinto del seguro de vida y a su ejercicio. Un acercamiento concreto podemos encontrarlo en el artículo 5, d) de la Directiva 73/239, el artículo 13.27) de la Directiva 2009/138 y Directivas 73/239 y 2009/138 añaden otra posibilidad: "Los Estados miembros podrán añadir a la categoría mencionada en el párrafo primero, letra c), los riesgos asegurados por asociaciones profesionales, empresas en participación o agrupaciones temporales".

${ }^{56}$ Contreras, cit. (n. 22), p. 133.

${ }^{57}$ Veiga, Abel, El Seguro. Hacia una reconfiguración del contrato. Cuadernos civitas, Thomson
} 
ponderar una serie de factores que se plasman en el contrato que parte de una asimetría informativa y profesional. ¿Cómo superar esta distancia? La información y una buena asesoría son relevantes en ello, ambas cuestiones que, sin embargo, competen a las aseguradoras (artículo 529 Cco.), pero este es un sujeto interesado en la contratación, de manera que está lejos de ser imparcial, y a ello debemos sumar que no existen criterios para entregar esta información de acuerdo a un estándar, ni existen criterios de evaluación de cumplimiento de esta carga, ni menos aún, una sanción que penalice su inejecución. Otra cuestión relevante, resulta ser la preparación de quienes entregan esta asesoría e información, materia que ha sido especialmente tratada por la CMF. ${ }^{58}$ En derecho comparado, esta materia se ha intentado reparar por la Unión Europea mediante Directivas que los distintos Estados han debido trasponer en sus legislaciones. Los principios europeos del contrato de seguro han exigido, por su parte, ${ }^{59}$ la obligación de la aseguradora de advertir al asegurado una serie de materias con el objeto de dar cumplimiento a su deber de informar, lo que a su vez, contribuye a la disminución de esta distorsión.

Frente a estas circunstancias, el contrato de seguro representa una oportunidad para corregir las deficiencias descritas.

La entidad aseguradora debiese incorporar un contenido similar del que habría resultado una negociación hecha en buenos términos, sobre la base de la buena fe y el respeto a la confianza, pero ¿cómo saber qué ello ha sucedido? Esta cuestión no se puede dejarse al puro arbitrio de quien redacta el contrato, pues - tal como señalamos- tratándose de un contrato por adhesión, resulta fundamental el rol legislativo en relación con el estándar que debe cumplir este dispositivo, bajo requisitos específicos que puedan verificarse con facilidad, y un papel de la entidad reguladora, tendiente a verificar que así ha sucedido. A ello, sumamos el rol de los tribunales, quienes tendrán la misión de interpretar el contrato, para luego verificar los posibles incumplimientos o inejecuciones de las obligaciones y cargas asumidas por las partes.

Ahora bien, siendo el contrato en general un mecanismo de distribución

Reuters, Navarra, 2018, pp. 20-21.

${ }^{58}$ NCG No 420, de 2007.

${ }^{59}$ VeIgA, Abel, "Hacia una Europóliza. Los principios de derecho europeo del contrato de seguro", RIS (Bogotá), 2012, 37 (21), pp. 61-95. 
de riesgos, resulta lógico pensar que en un contrato por adhesión los predisponentes deben asumir mayores cargas con el objeto de intentar -en la medida de lo posible- equilibrar el negocio jurídico.

Desde otra perspectiva, y considerando que el contrato de seguro tiene una serie de límites o delimitaciones que excluyen la obligación de la aseguradora de indemnizar al asegurado, debe estar muy claro cuáles son estas situaciones y, más aún, si ello se justifica. En tal sentido, la redacción del contrato y las condiciones generales de contratación, se tornan relevantes para una adecuada protección del contratante débil. Se ha señalado con justa razón que cualquier norma legal que trate de proteger al asegurado, tiene entre su articulado como máxima y denominador común, la exigencia de concreción, claridad, y sencillez en la redacción del clausulado. ${ }^{60}$ A esto se suman la prohibición de incorporar estipulaciones lesivas y el cumplimiento de ciertas exigencias para que el asegurado tenga claridad absoluta sobre lo que está firmando. En tal sentido, deben destacarse, por ejemplo, aquellas limitaciones que importan al momento del siniestro y del pago de la indemnización, y sancionar con eficacia las inexactitudes y vaguedades del contrato. También debiesen ser claras las consecuencias de la desinformación, la información falsa, errónea o inexacta que se da a conocer al asegurado, pues se trata de un instrumento financiero que influye en el correcto funcionamiento del mercado, de manera que el legislador debiese tomar especial atención a estos aspectos. ${ }^{61}$

Si revisamos el Cco. chileno, veremos que en su artículo 521 se dispone: "Nulidad. Son requisitos esenciales del contrato de seguro, el riesgo asegurado, la estipulación de prima y la obligación condicional del asegurador de indemnizar. La falta de uno o más de estos elementos acarrea la nulidad absoluta del contrato. Son nulos absolutamente también, los contratos que recaigan sobre objetos de ilicito comercio y sobre aquellos no expuestos al riesgo asegurado o que ya lo han corrido". De la lectura de este precepto, queda en evidencia que frente la vulneración de los requisitos esenciales del contrato se afecta, en principio, a ambos contratantes, en circunstancias que fue el asegurador quien redactó el contrato. En caso

\footnotetext{
${ }^{60}$ BATTELLI, Ettore, "Interpretatio contra preferentem e tranparenza contrattuale", Contratto e Impresa, 2017 volumen 33, $\mathrm{N}^{\circ} 1$, pp. 194-232.

${ }^{61}$ Sobre este tema: Veiga, Abel, Productos financieros y seguro. Más allá del riesgo de inversión ¿Quo Vadis?, Thomson Reuters, Navarra, 2020, pp. 195-196.
} 
de que este resulte nulo, el asegurado -quien se encuentra legitimado para solicitar esta sanción- no querrá solicitarla, pues resulta evidente que no le beneficia, por el contrario, se verá obligado a celebrar un nuevo contrato y nada asegura que podrá conseguirlo en condiciones similares, sobre todo si las circunstancias han cambiado. ¿Parece lógica esta norma? ¿No sería más sensato penalizar a la aseguradora, por ejemplo, con una indemnización al asegurado considerando los perjuicios que esta situación pueda causarle? Por otra parte, el código del ramo guarda total silencio sobre el carácter lesivo que puede tener para el asegurado una determinada cláusula contractual, y cómo deben redactarse las limitaciones a sus derechos, ni se pronuncia sobre qué debe entenderse como abusivo, lo que ciertamente resulta extraño si consideramos que las legislaciones que guiaron la redacción de la nueva ley sí contemplan estas materias (Ej. artículo $3^{\circ}$ de la Ley N50/1980).

El artículo 529 del Cco., establece que, el asegurador contrae las siguientes obligaciones: 1) Cuando el seguro fuere contratado en forma directa, sin intermediación de un corredor de seguros: prestar asesoría al asegurado, ofrecerle las coberturas más convenientes a sus necesidades e intereses, ilustrarlo sobre las condiciones del contrato y asistirlo durante toda la vigencia, modificación y renovación del contrato y al momento del siniestro. Cuando el seguro se contrate en esta forma, el asegurador será responsable de las infracciones, errores y omisiones cometidos y de los perjuicios causados a los asegurados. 2) Indemnizar el siniestro cubierto por la póliza. De ello resulta evidente que la legislación no señala una forma, un contenido, ni una sanción concreta frente a este incumplimiento, a diferencia de lo que ocurre con las cargas del asegurado que incluso pueden provocar la rescisión del contrato, aun cuando no exista dolo (artículo $525 \mathrm{Cco}$.). Tampoco resuelve el caso del seguro contratado de manera indirecta.

En relación a la existencia de cláusulas abusivas, el Cco. nada señala, de tal manera que debemos remitirnos a la LPC (artículo16). Sabemos que la abusividad se entiende contraria a la buena fe (que constituye fuente de integración del contenido contractual), pues provoca un detrimento en el adherente y un beneficio injusto a favor del predisponente. La doctrina ha criticado esta norma, por la ausencia de una sanción determinada, por cuanto la nulidad ${ }^{62}$ no se ajusta a los criterios y pautas del derecho

${ }^{62}$ Existe discusión sobre el tipo de nulidad o ineficacia a que da lugar el control de contenido de las cláusulas abusivas, debido a la vaguedad de la norma. Para algunos se trataría de una nulidad absoluta, 
común (artículos. 1681 y siguientes Cc.), sino a una especial forma de entenderla. ${ }^{63-64}$ Frente a la ausencia de criterios, debemos preguntarnos: ¿Cómo detectamos una cláusula abusiva en un contrato de seguro? ¿Cuándo estaremos en presencia de una cláusula que limita los derechos del asegurado arbitraria o injustamente, en concordancia con la delimitación de los riesgos y la consiguiente indemnización en caso de siniestro? ¿Hasta dónde puede llegar la interpretación del juez? ${ }^{65}$ ¿Qué valor ha de darse a los instrumentos pre y pos contractuales? ${ }^{66}$ Estas y otras interrogantes no son baladíes, pues el contrato de seguro es uno de los de mayor litigiosidad en la práctica. ${ }^{67}$ En nuestra opinión, debiera entenderse que una cláusula abusiva es, entre otras posibilidades, aquella que limita o restringe los derechos del asegurado injustificadamente. ${ }^{68-69}$ También tendrán este carácter, aquellas

para otros relativa o derechamente se refieren a una nulidad especial. Véase en: MoralEs, María Elisa, Veloso, Franco, "Cláusulas abusivas en la ley 19.496. Ley, doctrina y jurisprudencia", en: Morales, M., (Dir.), Derecho de consumo: Ley, doctrina y jurisprudencia, DER Ediciones, Santiago, 2019, pp. 149-164.

${ }^{63}$ Sobre la sanción y las normas por las que se rige, no existe completo consenso en la doctrina. En un fallo de la Corte de Apelaciones de Talca, Rol No 674-2014, se ha hecho referencia a la ineficacia, omitiendo la fundamentación de tal aserto, así como ha resuelto la condena por daño moral, por causa patrimonial. El comentario de dicho fallo se encuentra en: MomBerg, cit. (n. 8), pp. 279-287.

${ }^{64}$ Sobre esta materia véase: PIZARro, Carlos, "Facultad de dejar sin efecto, modificar a su solo arbitrio, o suspender unilateralmente la ejecución del contrato", en: De La Maza, I., Pizarro, C., (Dirs), La protección de los derechos de los consumidores. Comentarios a la ley de protección a los derechos de los consumidores, Editorial Thomson Reuters, Santiago, 2013, pp. 305-311.

${ }^{65}$ Sobre la interpretación del juez y sus posibles excesos: De Martín, Alberto, "Las condiciones generales como parte del contrato de seguro: interpretación judicial", Revista Española de Seguros: Publicación doctrinal de Derecho y Economía de los Seguros Privados, 2004, N¹17, pp. 47-70.

${ }^{66}$ VeIga, Abel, Tratado del Contrato de Seguro, Editorial Thomson Reuters, Pamplona, 2014., $6^{\circ}$ edición., T.1, pp. 1253-1254.

${ }^{67}$ EmBID, José, "Aspectos institucionales y contractuales de la tutela del asegurado en el derecho español”, Revista Española de Seguros: Publicación doctrinal de Derecho y Economía de los Seguros Privados, 1997, No 91, pp. 7, 14 y ss.

${ }^{68}$ La legislación española plantea que el contrato y las condiciones generales no pueden tener carácter lesivo para los asegurados. Las condiciones generales y particulares se redactarán de forma clara y precisa. Se destacarán de modo especial las cláusulas limitativas de los derechos de los asegurados, que deberán ser específicamente aceptadas por escrito. Las condiciones generales del contrato estarán sometidas a la vigilancia de la Administración Pública en los términos previstos por la Ley. Adicionalmente se plantea que, declarada por el Tribunal Supremo la nulidad de alguna de las cláusulas de las condiciones generales de un contrato, la Administración Pública competente obligará a los aseguradores a modificar las cláusulas idénticas contenidas en sus pólizas (artículo 3, Ley 50, 1980). Sobre qué ha de entenderse como carácter lesivo, la jurisprudencia ha despejado esta variable, entendiendo como tales aquellas cláusulas delimitativas de coberturas que no se encuentren aceptadas expresamente por el asegurado.

${ }^{69}$ En sentido: Sentencia del Tribunal Supremo Español, 29 de enero de 2019, Rol No (no se indica): 
que confieren derechos y facultades exorbitantes a favor del proponente; suprimen o reduzcan las obligaciones o responsabilidades del predisponente y/o se incrementen las obligaciones y cargas del adherente.

La CMF, al igual que su antecesora (SVS), tiene el rol de supervisar y regular las actividades y entidades que participan de los mercados de banca, valores y seguros en Chile. Para ello cuenta con una multiplicidad de funciones, como: la fiscalización y control respecto de las compañías aseguradoras y reaseguradoras; la función interpretativa, normativa e instructiva de los distintos cuerpos normativos que rigen a los actores del mercado de seguros; la labor investigativa y aclarativa respecto de eventuales consultas, solicitudes y reclamos interpuestos por los actores del mercado de seguro; un rol colaborativo en cuanto a la indagación de eventuales infracciones a la legislación de seguros vigentes que pudiesen solicitarle entidades reguladoras o fiscalizadoras extranjeras de acuerdo a convenios o instrumentos internacionales de cooperación, información, capacitación y asistencia recíproca y un rol de registro de todas las pólizas que se emitan en el país. ${ }^{70}$

Mediante norma de aplicación general, las disposiciones mínimas que deberán contener las pólizas y podrá prohibir la utilización de un modelo de póliza o cláusula cuando, a su juicio, su texto no cumpla con los requisitos de legalidad y claridad en su redacción, o con las disposiciones mínimas señaladas precedentemente. En la práctica, sin embargo, ejerce un control que no es eficiente. En efecto, si una determinada póliza adolece de errores o abusos, no se exige que este contrato deje de circular o se reemplace en todos ellos lo abusivo, por el contrario, se indica que la CMF en un examen preliminar podrá (y que en la práctica hace en forma reducida, por los escasos

https://elderecho.com/clausulas-delimitacion-cobertura-clausulas-limitativas-derechos-contrato-seguro, consultada: 15 de junio de 2021. En esta misma dirección, otra sentencia del Tribunal Supremo Español, Rol No (no se indica), 12 de diciembre de 2019: https:/www.mundojuridico.info/delimitacion-decobertura-y-clausulas-limitativas-en-el-contrato-de-seguro/ (visita: 15 de junio de 2021), expuso: "En principio, una condición delimitadora define el objeto del contrato, perfila el compromiso que asume la compañía aseguradora, de manera tal que, si el siniestro acaece fuera de dicha delimitación, positiva o negativamente explicitada en el contrato, no nace la obligación de la compañia aseguradora de hacerse cargo de su cobertura. Las cláusulas limitativas, por el contrario, desempeñan distinto papel, en tanto en cuanto producido el riesgo actúan para restringir, condicionar o modificar el derecho de resarcimiento del asegurado". En otras palabras, si la limitación es aceptada expresamente por el asegurado de acuerdo con el artículo. $3^{\circ}$ de la LGS, no se considerará abusiva.

${ }^{70}$ Artículos $1^{\circ}, 3^{\circ}$ y $5^{\circ}$ de la Ley No 21.000 , de 2017. 
días conferidos al efecto, ${ }^{71}$ de manera que es inexistente en la práctica ${ }^{72}$ ), prohibir la utilización del modelo. Si esto sucediera, tampoco se afectará a los contratos vigentes que pueden tener una cláusula análoga, sino que sólo a los que se suscriban con posterioridad a la declaración de prohibición. ${ }^{73}$ Se trata, claro está, de un control meramente formal ${ }^{74-75}$ que genera vacíos importantes y no alcanza el objetivo de proteger al asegurado-consumidor. La NCG N ${ }^{\circ} 349^{76}$ reitera lo ya señalado, en orden a que las condiciones generales deben estar escritas en idioma castellano y expresarse en términos de uso común y general. ${ }^{77}$ Lo mismo se indica respecto de las condiciones particulares, ${ }^{78}$ en el entendido que sólo se exige una buena redacción, que

${ }^{71}$ Esta cuestión ha variado con los años. Desde 1931, la SVS debía aprobar los modelos de póliza propuestos por las compañías. Desde 1980, se permitió que cada compañía redactara sus propias pólizas de acuerdo a la normativa vigente, las que debían ir acompañadas por un informe de legalidad de un abogado. Desde 2013, el registro no requiere aprobación, pero puede ser objeto de observación y prohibición.

${ }^{72}$ De acuerdo a la Resolución Exenta $N^{\circ} 169$, 2014, se han prohibido la utilización de 4 pólizas y 7 cláusulas. Véase en: Morales, María Elisa, "Acerca del control de la Superintendencia de Valores y Seguros sobre las pólizas", en: CARvaJal, L., Toso, Á., (Eds.), Estudios de Derecho Comercial, Octavas Jornadas Chilenas de Derecho Comercial VIII, Editorial Thomson Reuters, Santiago, 2018, p. 101.

${ }^{73}$ En caso de que un modelo de póliza o cláusula sea prohibido, su código se mantendrá en el Depósito asignándose el estado de "prohibido" junto con la referencia a la resolución de prohibición y su fecha.

${ }^{74}$ La excepción a esta regla la encontramos en los SOAP, Ley N $\mathrm{N}^{\mathrm{B}} 18.490$, de 1986, que deben ser aprobados por la CMF.

${ }^{75}$ En la práctica, sí las revisa con posterioridad e incluso decreta su prohibición, lo que nos parece lógico atendidas las reglas generales que consagran su facultad fiscalizadora (artículo 3 E del DFL N ${ }^{\circ}$ $251,1931)$ sin limitarla a un plazo determinado. A su vez, se debe considerar la jerarquía normativa del DFL en contraste con la NCG No 349, 2011, que nos lleva a pensar que el plazo de 6 días de que trata la norma administrativa es uno de los posibles controles que podría efectuar la CMF, pero dicha facultad fiscalizadora es permanente en el tiempo.

${ }^{76}$ NCG No 349, 2011.

${ }^{77}$ Los textos deberán contener las siguientes materias mínimas, exceptuando aquellas que no se apliquen al producto o tipo de seguro en el orden que se señala a continuación: a) Reglas aplicables al contrato, b) Cobertura y materia asegurada, c) Exclusiones, d) Obligaciones del asegurado, e) Agravación o alteración del riesgo, f) Declaraciones del asegurado, g) Prima y efectos del no pago de la prima, h) Denuncia de siniestros, i) Terminación, j) Comunicación entre las partes dentro del orden descrito anteriormente, se podrán intercalar estipulaciones relativas a otras materias, siempre que ello sea necesario para una mejor comprensión del contrato.

${ }^{78}$ De acuerdo a esta norma, se entenderá por condiciones particulares de la póliza de seguro, todas aquellas estipulaciones que regulan aspectos que por su naturaleza no sean materia de condiciones generales, y que permiten la singularización de una póliza de seguro determinada, especificando sus particularidades, tales como: requisitos de asegurabilidad o aseguramiento, especificación de la materia asegurada, individualización del asegurador, contratante, asegurado y beneficiario, si corresponde; descripción, destino, uso y ubicación del objeto o materia asegurada, monto o suma asegurada, prima convenida; lugar, tiempo y su forma de pago; franquicias, deducibles y duración del seguro (...). En las condiciones generales o particulares, según la naturaleza de la disposición, se deberán incluir las 
no sea inductiva a error y que no contenga cláusulas ilegales. ${ }^{79}$ Frente a posibles dudas, se señala que prevalecerá la interpretación más favorable al asegurado o al beneficiario, más no dispone qué ocurre si el contrato vulnera su derecho o si el contrato es inductivo a error. ${ }^{80}$

Si bien podría plantearse una modificación en la materia de forma que este organismo estatal (CMF) asuma funciones similares a la legislación española ${ }^{81}$ también es necesario conferir poderes a la judicatura para extrapolar la sentencia que declara la abusividad de un caso a otros de igual naturaleza. Con ello, el Estado y sus contribuyentes podrían ahorrar cuantiosos recursos en juicios que sólo replican la denuncia de una cláusula anómala y abusiva que ya fue reconocida como tal en un juicio anterior. Para entender la importancia de este punto, basta considerar que las cláusulas abusivas conllevan un desequilibrio contractual ${ }^{82}$ y un perjuicio al asegurado, lo que a la postre perjudica el funcionamiento del mercado y provoca problemas judiciales asumidos en buena medida por el Estado. ${ }^{83}$

Contrario a toda lógica, los jueces que plantea el Cco., como competentes para resolver estos y otros conflictos son los jueces árbitros (artículo 543 Cco.) y excepcionalmente la justicia estatal, lo que plantea nuevos inconvenientes porque no se requiere que sean jueces especialistas en la materia; se trata de una justicia pagada, lo que evidentemente desincentiva su puesta en marcha por consumidores; y porque estos jueces resuelven -por regla general- como arbitradores, de manera que fallan sobre principios de equidad.

exigencias previstas en el artículo 17 B) LPC y demás disposiciones que pudieran ser aplicables de dicha ley, cuando corresponda.

${ }^{79}$ Lo que se vincula con el principio de transparencia que va más allá de la información (artículo $3^{\circ} \mathrm{b}$ ) LPC). Sobre el tema, véase: Barrientos, cit. (n. 45), pp. 1001-1018; De La Maza, Iñigo, MomberG, Rodrigo, "La transparencia como mecanismo de tutela de la privacidad de los consumidores y usuarios en contratos electrónicos", Revista Chilena de Derecho y Tecnología, 2018, Vol. 7, N² 2, pp. 81-111.

${ }^{80}$ A diferencia de lo que ocurre con el asegurador, que presenta una expresa protección respecto de la información que le entregue el asegurado (artículos 524, 525 y 539 Cco.). En estos casos, y considerando que no existe norma particular sobre esta materia, debiésemos aplicar las normas generales, de manera tal que si el contrato transgrede la ley de seguro la sanción será la nulidad; y si es inductivo a error respecto del tomador o asegurado habrá que analizarse si ello vicia el consentimiento brindado.

${ }^{81}$ En un sentido similar: CONTRERAs, cit. (n. 22), pp. 195-196.

${ }^{82}$ Concordamos con: Carrasco, Ángel, Derecho de contratos, Editorial Aranzadi, Pamplona, 2017, p. 774 .

El referido autor señala que el principio de autonomía de la voluntad no es suficiente para legitimar un acuerdo, si este no ha sido creado por un procedimiento adecuado.

${ }^{83}$ VeIGA, cit. (n. 65), p. 1266. 
Frente a esta realidad, no han sido escasos los recursos de protección que los asegurados han intentado directamente en las Cortes de Apelaciones en la búsqueda de protección de sus derechos fundamentales, lo que ha significado una intervención en las relaciones jurídicas entre particulares ${ }^{84}$ en la medida en que el juez de tutela puede interpretar, modificar, resolver el contrato, si con ello protege un derecho fundamental de un particular en situación de indefensión, inferioridad y subordinación frente a otro. ${ }^{85}$

Otro camino que podría implementarse para la protección del asegurado, es el resguardo de la libre competencia entre las aseguradoras. Los modelos de póliza depositados se reproducen a gran escala, de manera que no es posible observar una alta competencia entre las compañías, lo que en definitiva provoca una alteración en el mercado. ${ }^{86}$ En tal sentido, resulta lógico incentivar la competencia entre aquellas, por ejemplo, ofreciendo comparaciones que se centren en las prestaciones asumidas vs primas (Por ejemplo: Coberturas ofrecidas), a fin de que los asegurados decidan con mayor información, y se informe a los futuros tomadores o asegurados sobre reclamos y conflictos suscitados con las compañías y cómo se han resuelto. Este tipo de medidas llenaría de contenido la adecuada asesoría que debe recibir el asegurado, pues esto aún se encuentra débilmente implementado (artículo 529 Cco.).

\footnotetext{
${ }^{84}$ CArdoso, Catalina, "La limitación de la autonomía privada de las compañías aseguradoras como mecanismo de protección del asegurado", Revista CES Derecho, 2014, Vol. 5, № 1, pp. 94-105.

${ }^{85}$ La Corte de Apelaciones de Concepción, 19 de junio de 2014, Rol N 19417-2013, resolvió: “(...) De esta forma, estamos ante un contrato que, en algunos de sus aspectos, se encuentra regido por la normativa propia del Derecho del Consumo. Específicamente, debe tenerse presente el artículo 16 letra a) de la ley 19.496, que viene a establecer un control al contenido de las cláusulas de los contratos de adhesión regidos por la ley de Protección al Consumidor, norma que señala expresamente: "No producirán efecto alguno en los contratos de adhesión las cláusulas o estipulaciones que le otorguen a una de las partes la facultad de dejar sin efecto o modificar a su sólo arbitrio el contrato o de suspender unilateralmente su ejecución (...)". En consecuencia, es posible concluir que resulta ilegal la actuación de la Compañía Aseguradora en orden a poner término unilateral a la Cláusula Adicional de Prestaciones Médicas "Cobertura de Salud Segunda Vida Ejecutivo", desde el momento que el artículo 16 letra a) de la ley ya citada, resta todo valor a las disposiciones contractuales que otorguen a una de las partes (y en especial al proveedor), la facultad de poner término unilateral al contrato". En otras palabras, es ilegal la decisión de la recurrida de poner fin a la Cláusula Adicional de Prestaciones Médicas... $9^{\circ}$.Que la infracción legal antedicha vulnera la garantía constitucional del derecho de propiedad del recurrente, consagrado en el artículo $19 \mathrm{~N}^{\circ} 24$ de la Constitución Política. Además, tal actuación ilegal, constituye, a lo menos, una amenaza indirecta a la vida o a la integridad física y síquica de la parte recurrente, amparados en el artículo $19 \mathrm{~N}^{\circ} 1$ de nuestra Carta Fundamental. En consecuencia, la protección impetrada habrá de prosperar (...) se deja sin efecto la no renovación y término del contrato de salud entre la recurrente y la recurrida".

${ }^{86}$ Morán, Manuel, "Derecho de la competencia y mercado de seguros: un año sin reglamentos de exención", Revista de Derecho UNED, 2018, № 23, pp. 493-525.
} 
V. TERCER MECANISMO DE PROTECCIÓN: CAUCE PROCESAL. SISTEMAS DE SOLUCIÓN DE LITIGIOS OFRECIDOS AL ASEGURADO PARA TUTELAR SUS DERECHOS

Como señalamos, el legislador plantea un arbitraje forzoso del que sólo puede abstraerse el asegurado respecto de ciertos conflictos (artículo 543 Cco.), siempre y cuando el valor del siniestro sea superior a 10.000 UF. Nótese que esta delimitación subjetiva no se efectúa considerando la calidad de este sujeto en cuanto consumidor, sino que sólo en virtud del monto reclamado por el siniestro, lo que desde luego resulta inconsistente a la luz de los objetivos previstos en la reforma. Por otra parte, el artículo 543 no guarda coherencia con la LPC, puesto que no sólo plantea un tribunal competente totalmente diferente (justicia de policía local y ordinaria dependiendo del caso), sino -y más grave aún- porque el artículo16 LPC dispone que el consumidor siempre puede renunciar unilateralmente a una cláusula de arbitraje contenida en un contrato por adhesión o bien recusar al árbitro respectivo.

¿Cómo se concilia el mecanismo de protección del artículo 542 Cco. (imperatividad) con el arbitraje forzoso establecido en el artículo 543 Cco.? Esta relación no resulta coherente ni consistente, de manera que no parece extraño que los asegurados -revistiendo la calidad de consumidores- busquen amparo en la LPC y la justicia allí establecida. La huida de este sistema resulta razonable, si consideramos el escaso margen de actuación que tienen los asegurados para acudir a la justicia estatal de acuerdo al artículo 543 y los costos que la justicia arbitral implica, lo que va en desmedro sólo del asegurado.

Por otra parte, esto se traduce en una latente vulneración de un derecho fundamental, al privar al contratante débil de la posibilidad de acudir a su justicia natural, que no es otra que la estatal (artículo $19 \mathrm{~N}^{\mathrm{o}} 3$, Constitución Política de la República, 1980), de manera que se restringe su tutela jurídica efectiva, sin ningún fundamento plausible. ${ }^{87}$

Este escenario pone en evidencia el desconocimiento sistemático por parte del legislador de dos cuestiones que resultan esenciales, a saber: 1. El

\footnotetext{
${ }^{87}$ Véase: VÁSQUEZ, María Fernanda, "Solución de conflictos en el contrato de seguro: algunos problemas que se plantean a partir del sistema actual y su coexistencia con el régimen de consumo. Una propuesta de interpretación y reconstrucción", Revista de Derecho Universidad de Concepción, 2018, Vol. 86, $\mathrm{N}^{\mathrm{o}} 244$, pp. 129-176.
} 
debido reconocimiento de la justicia arbitral desde la autonomía de la voluntad de las partes, de manera que la idea de su forzamiento resulta antijurídica y, 2. El derecho de toda persona en orden a acceder a la justicia natural que es estatal, lo que desde luego es un derecho fundamental. Estos dos alcances se encuentran ampliamente reconocidos en el derecho comparado y resulta inverosímil que la legislación chilena continúe incrementando el elenco de materias de arbitrajes forzosos.

No bastando ello, además debemos lidiar con la calidad que el artículo 543 Cco., otorga al árbitro, que es la de "arbitrador", lo que implica que éste podrá fallar en equidad para resolver los conflictos, desdibujado inmediatamente la imperatividad que resguarda el artículo 542 Cco. El arbitraje seguido por un árbitro arbitrador presenta, por su parte, dos características que no se concilian con este sistema de imperatividad: 1 . Las sentencias o laudos arbitrales pueden pronunciarse en equidad, lo que implica que no tienen un deber irrestricto en orden a fallar en derecho, sino de acuerdo a lo que su prudencia le dicte; y 2. Los fallos arbitrales no pueden ser recurridos ante los tribunales estatales, a diferencia de lo que ocurre en los arbitrajes de derecho y mixtos, donde caben todos los recursos. En este arbitraje sólo es posible intentar la casación en la forma por causales muy estrictas (ultra petita e incompetencia).

Otro de los problemas que conlleva este sistema, es la inexistencia de publicidad de las sentencias arbitrales, pues si bien algunas se publican en la $\mathrm{CMF}$, no es la regla general.

Esto nos lleva a concluir que el estatuto de tutela del aseguradoconsumidor no fue analizado en profundidad por el legislador, por lo que anhelamos su pronta enmienda. Siguiendo los derechos más avanzados en la materia -ignoramos la razón de este olvido- debiésemos crear tribunales gratuitos y especializados en materias de consumo-seguro, que den cumplimiento a las garantías o tutelas que requiere el contratante débil en este contrato, mientras ello no suceda, esperamos que los jueces árbitros, con independencia de su carácter, den estricto cumplimiento a lo dispuesto en el artículo 542 del Cco.

Como señalamos, en casos excepcionales que dicen relación con la cuantía del siniestro, los asegurados podrían ocurrir ante la justicia ordinaria, pero de acuerdo a las normas de la LPC, también pueden acudir a los Juzgados de Policía Local, que contempla un procedimiento al amparo de la LPC. No existe contradicción entre estas judicaturas, pues cada una se 
avoca a la protección de materias de diversa índole, de forma que aplicando el principio pro consumatore y la imposibilidad de renunciar a sus derechos, estimamos que el consumidor podría acudir a cualquiera de los tribunales establecidos a estos efectos, dependiendo de su alegación particular y la norma que resulte aplicable. Así, por ejemplo, en cuanto a la formación del contrato, no sólo resultan aplicables los artículos 512, 515 y 516 del Cco., pues ellos no aseguran de manera íntegra el acceso por parte del aseguradoconsumidor a la información y menos garantizan la oportunidad para llegar a aquella, de manera que también serán aplicables los artículos 12 y 12 A de la LPC. ${ }^{88}$

A su vez, la misma LPC contempla diferentes herramientas que pueden ser utilizadas por el asegurado. Previo al conflicto encontramos la mal llamada "mediación" que realiza el Servicio Nacional del Consumidor (SERNAC) en uso de sus facultades protectoras de los derechos de los consumidores, que en la práctica no es una mediación propiamente tal, sino sólo un canal que tiene por objeto otorgar la posibilidad de que el consumidor pueda reclamar al proveedor y éste responder de tal reclamo; si ello no se logra, el consumidor puede activar un mecanismo judicial o simplemente no hacer nada, frente a lo cual resulta del todo lógico considerar que la herramienta no es eficaz. En esta misma línea, podemos encontrar el sello otorgado por el SERNAC (introducido a partir de la Ley $\mathrm{N}^{0} 20.555$, de 2011) a los contratos por adhesión de proveedores financieros, como una especie de certificación de legalidad antes que los contratos sean utilizados por los proveedores.

Finalmente, recordemos que la CMF mantiene un control permanente respecto de las aseguradoras, de manera que los asegurados podrían recurrir ante ella u otras instituciones como el "Defensor del asegurado", ${ }^{89}$ para

\footnotetext{
${ }^{88}$ Sobre esta materia podemos citar la causa conocida por la Corte de Apelaciones de Antofagasta, 7 de mayo de 2015, Rol No 48-2015, donde se discutió la competencia para conocer de los conflictos derivados del contrato de seguros. Se indicó que de conformidad a lo dispuesto en el artículo 543 inciso $3^{\circ}$ del Código de Comercio, a partir de la modificación introducida por la Ley $\mathrm{N}^{\circ} 20.667$, de 2013, existe un derecho del asegurado en orden a escoger la justicia que les parezca mejor a sus intereses, de este modo, de manera clara la ley ha otorgado un derecho de opción al asegurado posibilitando en el caso señalado hacer valer sus pretensiones derechamente ante la justicia ordinaria, o bien, ante el sistema arbitral establecido como mecanismo general de solución de conflictos por el Código de Comercio.

${ }^{89}$ En el mismo sentido, en una resolución del Defensor del asegurado, se señaló: "La controversia sometida a la decisión de este Defensor está centrada en la validez de la decisión de no renovar automáticamente a su vencimiento la póliza de seguro contratada por el señor Iván Quezada Viera
} 
hacer valer algún derecho. Con todo, esta es una herramienta que no parece haber tenido el impacto esperado.

Otro mecanismo que puede activar el asegurado-consumidor puede verse desde la óptica de sus derechos fundamentales, en lo que podríamos calificar como la constitucionalización de la defensa de estos derechos. ${ }^{90} \mathrm{En}$ la práctica se presentan recursos de protección fundados en la vulneración del derecho de propiedad (seguro de daños) o de la vida (seguro de personas), en aquellos supuestos en que las compañías aseguradoras dejen de prestar el servicio contratado de manera unilateral, lo que configura una vía adicional muy atractiva por su eficacia. ${ }^{91}$

En otras palabras, el asegurado podría acudir a la justicia arbitral, ordinaria, de policía local e inclusive a la Corte de Apelaciones respectiva. Por supuesto, habrá que discernir cuestiones relacionadas a la materia, ámbito de aplicación y oportunidad procesal, ${ }^{92}$ pero parece sensato considerar que este abanico de posibilidades ${ }^{93}$ no resulta beneficioso para el asegurado,

$y$, en consecuencia, en la procedencia de la liquidación del siniestro denunciado por éste estando en desconocimiento de la terminación de su contrato". Se debía resolver si la falta de uno de los datos para la individualización del vehículo, en este caso su placa patente, es o no un requisito cuya falta pudiera liberar a la aseguradora de sus responsabilidades contractuales, de acuerdo a lo prescrito en el acuerdo de renovación automática de la póliza. Resolución sobre el Reclamo 02-1532-2012 presentado por el señor Iván Quezada Viera en contra de MAPFRE Compañía de Seguros Generales de Chile S.A., por la no renovación automática de su Póliza de Seguros para Vehículos Motorizados No 2 801-1 1-00143334.

${ }^{90}$ ZARANTE, Gabriela, "Constitucionalización y protección de derechos fundamentales en el contrato de seguros. Análisis jurisprudencial - corte constitucional de Colombia", Revista Ibero-Latinoamericana De Seguros, 2016, Vol. 25, n 45, pp. 233-268

${ }^{91}$ En este sentido: Corte de Apelaciones de Concepción, 19 de junio de 2014, Rol No 19350-2013.

${ }^{92}$ A modo de ejemplar véase: Juzgado de Policía Local de Vitacura, 15 de enero de 2018, Rol N ${ }^{\circ}$ 625-724-15. En este caso el asegurado (Transportes, arriendo de maquinaria y construcción SpA o Transmaco) interpuso una demanda por nulidad de un contrato de seguro por existir cláusulas abusivas y una querella por infracción en contra de la aseguradora Mapfre Compañía de Seguros Generales SA. Funda sus acciones en que la aseguradora habría rechazado el pago de un siniestro por cuanto el cargador asegurado, que fue robado, se encontraba en un lugar diferente al momento del robo respecto de la ubicación asegurada en la póliza. El demandado, a su vez, presenta una excepción dilatoria en razón que en la póliza se estipula como tribunal competencia a un árbitro arbitrador. El juez de Policía Local que conoce de este juicio se declaró incompetente por no estar señalado el lugar donde se celebró el contrato.

${ }^{93}$ En este sentido podemos distinguir controles inclusivos interpretativos y de contenido. El primero busca garantizar que el consumidor esté en condiciones de obtener la información necesaria antes de suscribir el contrato, lo que supone una serie de requisitos formales que debe contener la cláusula. A modo de ejemplo podemos observar sobre el primer grupo, los artículos $12 \mathrm{~A}, 17$ y $17 \mathrm{~B}$, este último exige que los contratos de adhesión estén escritos de modo claramente legible, de manera que, si no lo está, no producirá efecto alguno respecto del consumidor. En cuanto al segundo, podemos mencionar el principio de prevalencia recogido en el artículo 17 inciso $2^{\circ}$ de la LPC, aplicable a los contratos 
pues éste deberá ponderar diversos aspectos en su decisión sin tener certeza sobre cuál será el mecanismo más conveniente o beneficioso a sus intereses. En tal sentido, somos partidarios de introducir modificaciones en el sistema vigente y crear un solo órgano competente para conocer los posibles conflictos que puedan suscitarse, de carácter gratuito y especializado, $\mathrm{y}$ que tenga en vista la tutela del asegurado para ser coherente y consistente la pretendida protección de este último. Asimismo, consideramos que la adecuada protección del asegurado requiere de sanciones efectivas a los predisponentes, lo que hasta hoy no sucede. Por ejemplo, la determinación de una cláusula abusiva, limitativa u oscura, que se declara como tal, sólo tiene efecto en el juicio en cuestión, y solo podrá aplicarse con un efecto expansivo en la medida que otras personas se hagan parte del mismo (artículo 54 LPC). Si tuviese un efecto erga omnes -como sucede en las legislaciones más avanzadas- se podría evitar la proliferación de juicios y pérdidas de recursos, logrando una efectiva protección del aseguradoconsumidor. Otro tanto ocurre con los contornos de la responsabilidad, pues si bien puede detectarse y sancionarse una cláusula abusiva, ello no genera ninguna sanción concreta para la compañía. ${ }^{94}$

\section{UNA PROPUESTA EN ARAS DE PERFECCIONAR EL ACTUAL SISTEMA JURÍDICO}

A partir de la entrada en vigor de la Ley $\mathrm{N}^{0} 20.667,2013$ y a pesar de su objetivo, hemos podido constatar que el legislador ha construido un estatuto jurídico protector del asegurado desarticulado e inconsistente. Esto ya se puede apreciar en un deber de información por parte del asegurador ambiguo e ineficiente; una redacción del contrato con carencias importantes (DFL N $\mathrm{N}^{\mathrm{2}}$ 251, 1931 y NGC $\mathrm{N}^{\circ} 349,2011$ ), una imperatividad indeleble (artículo 542 Cco.), que sólo es posible salvar a partir de la aplicación de

por adhesión impresos en formularios y según la cual "prevalecerán las cláusulas que se agreguen por sobre las del formulario cuando sean incompatibles entre sí”. Este control descansa en la primacía de la regla contra proferentem, aún cuando no posee un texto expreso en la LPC, pero si en el DFL $\mathrm{N}^{\circ}$ 251, 1931 y en la NCG No 349, 2011 de acuerdo con lo visto. A ello debemos agregar lo dispuesto en el artículo 1566 CC. Finalmente, el control de contenido versa sobre las cláusulas del contrato y las condiciones generales de la contratación. Sobre esta materia: LóPEz, Patricia, Tutela precontractual del acreedor, Thomson Reuters, Santiago, 2019.

${ }^{94}$ Véase: Corte Suprema, 21 de enero de 2019, Rol № 34507-2017. 
la LPC, y un arbitraje forzoso (artículo 543 Cco.) que en nada beneficia al asegurado.

Han transcurrido cerca de 8 años y es tiempo de evaluar esta normativa. De lege ferenda estimamos que debiesen efectuarse las siguientes modificaciones:

a. Reforzar las obligaciones y cargas del asegurador en concordancia con un sistema de responsabilidad efectivo.

b. Revisar y modificar las cargas y consecuencias de su inejecución que corresponden al asegurado, de manera que sean coherentes con los propósitos del contrato.

c. En relación con las condiciones generales, debiese declararse de manera expresa (tal como lo hace el artículo $3^{\circ}$ de la Ley 50/1980 (España), en la que se basó la ley chilena), que en ningún caso podrán tener carácter lesivo para los asegurados, y que deberán incluirse por el asegurador tanto en la proposición de seguro (si es que la hubiere) y en la póliza o en un documento complementario, que debiese ser suscrito por el asegurado, debiendo entregársele copia del mismo. Las condiciones generales y particulares además de ser redactadas en forma clara y precisa, deberán ser destacadas de manera especial en aquella parte que limiten los derechos de los asegurados, ${ }^{95}$ las que, a su vez, deberán ser específicamente aceptadas por escrito.

d. En el mismo sentido, debiera indicarse, al igual como se señala en el precepto en cita que, declarada por el tribunal respectivo la nulidad de alguna de las cláusulas de las condiciones generales de un contrato, la CMF obligará a los aseguradores a modificar las cláusulas idénticas contenidas en sus respectivas pólizas.

e. Incrementar la seguridad jurídica del régimen de condiciones generales del contrato, mediante un control efectivo de incorporación, transparencia, comprensibilidad, concreción y contenido.

f. La interpretación del contrato debiese tener reglas hermenéuticas de prevalencia moduladas por la condición más beneficiosa para

\footnotetext{
${ }^{95}$ En este punto, destacamos lo dispuesto por las normas del Estatuto Orgánico del Sistema Financiero y otros instrumentos del sistema colombiano que establecen la carga de que las exclusiones deban figurar en la primera página de la póliza so pena de ineficacia de la estipulación respectiva. Para un mayor análisis véase en: VÁsQuEz, Daniel, "La cargas de establecer las exclusiones el contrato de seguro en la primera página de la póliza”, Rev.Ibero-Latinoam.Seguros, Bogotá, 2020, Vol. 29 (53), pp. 15-38.
} 
el asegurado, de manera que las condiciones particulares primen sobre las generales, salvo que ocurra lo contrario. ${ }^{96}$

g. El control de contenido que debe efectuar la CMF debiese distinguir entre condiciones generales de la contratación entre profesionales $\mathrm{y}$ las que se establezcan con consumidores, donde debiese establecerse que se considerarán abusivas las estipulaciones no consentidas expresamente, que vayan en perjuicio del asegurado o beneficiario, o provoquen un desequilibrio entre los derechos y obligaciones ${ }^{97}$ También habría que insertar la regla de lesividad, señalando qué se entiende como tal, y una consecuencia de aquellas, por ejemplo, que estas cláusulas se entiendan nulas sin afectar al contrato del que forman parte.

h. Establecer un modus operandi respecto de la asesoría e información que debe otorgar el asegurador al asegurado, tomador y beneficiario, a fin de establecer de manera cómo y cuándo se cumple este deber. Esto debiese ser objetivado por medio de un procedimiento, y su vulneración debiese tener una sanción que resguarde los derechos del asegurado.

i. Suprimir el mecanismo de arbitraje forzoso que se plantea en el artículo 543, creando tribunales especiales y gratuitos o, en su defecto, que los tribunales estatales conozcan de estas controversias. En este sentido, destaca lo expuesto por el artículo 24 de la Ley N50/1980 (España), que sólo indica que será juez competente para el conocimiento de las acciones derivadas del contrato de seguro es el del domicilio del asegurado, siendo nulo cualquier pacto en contrario.

j. Reservar la sanción de nulidad sólo para casos excepcionales, considerando que no es la mejor forma de proteger al contratante débil según se expuso. En tal sentido, debemos recordar que de acuerdo al art. $4^{\circ}$ de la Ley $\mathrm{N}^{\circ} 50 / 1980$ (España), el contrato de seguro será nulo, si en el momento de su conclusión no existía el riesgo o había ocurrido el siniestro.

k. Establecer disposiciones que prohíban toda discriminación en la

\footnotetext{
${ }^{96}$ En este sentido: VÁsquez, María Fernanda, Contrato de Seguro. Doctrina y jurisprudencia, Tirant lo Blanch, Valencia, 2019.

${ }^{97}$ En esta línea: Bataller, cit. (n. 19), pp. 347 y ss.
} 
contratación de seguro..$^{98}$

1. Establecer mayores rigurosidades frente a la contratación de seguros por vía indirecta.

En este orden de ideas, consideramos que mientras no se efectúen las reformas respectivas, debe regir íntegramente el principio de protección o a favor del asegurado.

\section{CONCLUSIÓN}

Al revisar tres mecanismos de tutela creados por la última reforma al contrato de seguro, es posible detectar diversos problemas en su construcción, lo que provoca que estas herramientas se tornen inconsistentes y no logren los objetivos pretendidos inicialmente. En esta tesitura, y a diferencia de lo que ocurre con los sistemas jurídicos que sirvieron de inspiración a la legislación chilena, la tutela jurídica del asegurador es feble e ineficiente.

Mientras esta situación no se modifique, abogamos por una adecuada interpretación de estos mecanismos de tutela en resguardo del consumidor. De lefe ferenda, el legislador debe tomar una posición clara, comprendiendo que siendo el contrato de seguro normalmente por adhesión y que, como tal, opera como un mecanismo de distribución de riesgos, resulta necesario que el predisponente/asegurador asuma mayores cargas y constriña la redacción del contrato de seguro en favor del aseguramiento eficaz de la protección del asegurado, con el objeto de desdibujar las asimetrías que existen en esta relación jurídica.

En conclusión, el Cco., si bien trazó una ruta en la necesidad de proteger la voluntad de las partes y la distribución de los riesgos, el camino ha quedado a medio perfilar. Por el momento, debemos complementar estas medidas a partir de otras normas que en su conjunto podemos vislumbrar como un sistema normativo protector. ${ }^{99}$

\footnotetext{
${ }^{98}$ Véase: TIRADO, Francisco, "La crisis del principio de la libre selección de asegurados. La cobertura de los menores, discapacitados, de los mayores y de determinados enfermos", en: VeIGA, A. (Dir.), Martínez, M. (Coord.), Retos y Desafios del contrato de seguro: Del necesario aggiornamento a la metamorfosis del contrato. Libro homenaje al profesor Rubén Stiglitz, Cátedra Uría Menéndez -ICADE de Regulación de los Mercados. Parte III. Protección de consumidores, Thomson Reuters, Navarra, 2020, pp. 433 y ss.

${ }^{99}$ Algunos de estos vacíos debieran ser resueltos por las normas del CC. (artículos 10, 12, 1445, 1566, entre otros); y la LPC, en especial las relativas a cláusulas abusivas y derechos del asegurado-consumidor
} 


\section{BIBLIOGRAFÍA}

\section{a) Doctrina}

BARAONA, Jorge, "Concepto, autonomía y principios del derecho de consumo", en: Morales, M. (Dir.) Derecho del consumo: Ley, doctrina y jurisprudencia, Der Ediciones Limitada, Santiago, 2019, pp. 1-24

Barrientos, Francisca, "¿Cómo se insertan los servicios médicos en el ámbito de la Ley sobre protección de los derechos de los consumidores?", Revista de Ciencias Sociales, 2018, No 73, pp. 133-152.

Barrientos, Francisca, "La responsabilidad civil del fabricante bajo el artículo 23 de la ley de protección de los derechos de los consumidores y su relación con la responsabilidad civil del vendedor", Revista Chilena de Derecho Privado, 2010, N¹4, pp. 109-158.

BARRIENTOS, Francisca, "Repensando el control de forma de los contratos por adhesión: una mirada a su aplicación actual y la introducción de la transparencia", en: Bahamondes, C., Etcheberry, L., Pizarro, C., (Eds.), Estudios de Derecho Civil XIII, Thomson Reuters, Santiago, 2018, pp. 1001-1018.

BARrientos, Marcelo, "La unilateral imperatividad de los requisitos esenciales del contrato de seguro en el código de comercio chileno", Rev. Bol. de Derecho, 2016, No 22, pp. 98-119.

Bataller, Juan, "Una mejor protección del asegurado es posible", en: Girgado, P. (Dir.), El contrato de seguro y su distribución en la encrucijada, Editorial Aranzadi, Navarra, 2018, pp. 347-375.

Battelli, Ettore, "Interpretatio contra preferentem e tranparenza contrattuale", Contratto e Impresa, 2017, Vol. 33, N 1, pp. 194-232.

CARDOSo, Catalina, "La limitación de la autonomía privada de las compañías aseguradoras como mecanismo de protección del asegurado", Revista CES Derecho, 2014, volumen 5, No 1, pp. 94-105.

Carrasco, Ángel, Derecho de contratos, Editorial Aranzadi, Pamplona, 2017.

Contreras, Osvaldo, Derecho de seguros, Thomson Reuters, Santiago, 2020, $4^{\circ}$ Edición.

Contreras, Osvaldo, El contrato de seguro, Thomson Reuters, La Ley, Santiago, 2002, $1^{\circ}$ Edición.

Contreras, Osvaldo. Derecho de Seguros, Thomson Reuters, La Ley, Santiago 2014, $2^{\circ}$ Edición.

(a la libre elección del servicio, a información veraz y oportuna; a la no discriminación; a la seguridad; al retracto para casos generales; entre otros). Sólo desde este conjunto normativo podemos vislumbrar un estatuto jurídico de protección del asegurado-consumidor más robusto. 
De La Maza, Iñigo, Momberg, Rodrigo, "La transparencia como mecanismo de tutela de la privacidad de los consumidores y usuarios en contratos electrónicos", Revista Chilena de Derecho y Tecnología, 2018, Vol. 7, № 2, pp. 81-111.

De Martín, Alberto, "Las condiciones generales como parte del contrato de seguro: interpretación judicial", Revista Española de Seguros: Publicación doctrinal de Derecho y Economía de los Seguros Privados, 2004, N¹17, pp. 4770 .

EmBID, José, "Aspectos institucionales y contractuales de la tutela del asegurado en el derecho español", Revista Española de Seguros: Publicación doctrinal de Derecho y Economía de los Seguros Privados, 1997, No 91, pp. 7-32.

Embid, José, "Preliminar", en: Boquera, J., Ballater, J., Olavarría, J. (Coords.), Comentarios a la ley de contratos de seguros, Editorial Tirant lo Blanch, Valencia, 2002, pp. 49-88.

IsLeR, Erika, Derecho del consumo. Nociones fundamentales, Tirant lo Blanch, Valencia, 2019.

JARA, Rony, "Ámbito de aplicación de la ley chilena de protección al consumidor inclusiones y exclusiones", en: Corral, H., (Ed.) Derecho del consumo y protección al consumidor. Estudios sobre la Ley $N^{o} 19.496$ y las principales tendencias extranjeras. Cuadernos de Extensión Jurídica, Ediciones Universidad de los Andes, Santiago, 1999, No 3, pp. 47-74.

Lagos, Osvaldo, "La reforma al derecho del contrato de seguros", Revista Chilena de Derecho de Seguros, 2014, pp. 27-57.

LARRAín, Carlos, "Sentido y alcance del principio de imperatividad de las normas legales relativas al contrato de seguro", Revista Chilena de Derecho de Seguros, 2015, №24, pp. 213-223.

LóPEZ, Patricia, Tutela precontractual del acreedor, Thomson Reuters, Santiago, 2019.

Martínez, Fernando, "La protección del asegurado en la jurisprudencia del Tribunal Supremo", en: Veiga, A. (Dir.), Martínez, M. (Coord.), Retos y Desafios del contrato de seguro: Del necesario aggiornamento a la metamorfosis del contrato. Libro homenaje al profesor Rubén Stiglitz, Cátedra Uría Menéndez ICADE de Regulación de los Mercados. Parte III. Protección de consumidores, Thomson Reuters, Navarra, 2020, pp. 563-588.

Mendoza, Pamela, Morales, María Elisa, "Notas sobre el control de cláusulas abusivas entre empresarios. Una síntesis del modelo alemán", Revista Chilena de Derecho Privado, 2020, No 34, pp. 207-216.

Momberg, Rodrigo, “Art. $2^{\circ}$ ”, en: De La Maza, I., Pizarro, C. (Dirs.), La protección de los derechos de los consumidores. Comentarios a la ley de protección de los consumidores, Thomson Reuters, Santiago, 2014, pp. 66-75.

Momberg, Rodrigo, "Definición de consumidores o usuarios" y "Definición de proveedores", en: De la Maza, I., Pizarro, C. (Dirs.), La protección de 
los derechos de los consumidores. Comentarios a la ley de protección de os consumidores, Thomson Reuters, Santiago, 2014, pp. 3-21.

Momberg, Rodrigo, "Derecho de Consumo: La empresa como consumidora: ámbito de aplicación de la LPC, nulidad de cláusulas abusivas y daño moral. Corte de Apelaciones de Talca, Rol No 674-2014 y Corte Suprema, Rol No 31-709-14", Revista de Derecho Privado, 2015, º25, pp. 279-287.

Momberg, Rodrigo, "Leyes especiales y aplicación de la ley 19.496 sobre protección de los derechos de los consumidores. Análisis de casos", en: Morales, M., (Dir.) Derecho del consumo: Ley, doctrina y jurisprudencia, DER Ediciones, Santiago, 2019, pp. 25-45.

Morales, María Elisa, "Acerca del control de la Superintendencia de Valores y Seguros sobre las pólizas", en: Carvajal, L., Toso, Á., (Eds.), Estudios de Derecho Comercial, Octavas Jornadas Chilenas de Derecho Comercial VIII, Thomson Reuters, Santiago, 2018, pp. 87-108.

Morales, María Elisa, Veloso, Franco, "Cláusulas abusivas en la ley 19.496. Ley, doctrina y jurisprudencia", en: Morales, M., (Dir.), Derecho de consumo: Ley, doctrina y jurisprudencia, Der Ediciones Limitada, Santiago, 2019, pp. 149164.

Morán, Manuel, "Derecho de la competencia y mercado de seguros: un año sin reglamentos de exención", Revista de Derecho UNED, 2018, № 23, pp. 493525 .

Morillas, María José, "Las normas sobre el contrato del seguro como ley general imperativa: Límites y excepciones, en particular, la referida a los seguros de grandes riesgos. Una aproximación al Art. 581-2 del anteproyecto código mercantil”, en: Morillas, M., Perales, M., Porfirio, L., (Dirs.), Estudios sobre el futuro Código Mercantil: libro homenaje al profesor Rafael Illescas Ortiz, Universidad Carlos III de Madrid, 2015, pp. 1556-1590.

PertíñEZ, Francisco, "Tutela de los consumidores y cláusulas abusivas en el contrato de seguro", en: Veiga, A. (Dir.), Martínez, M. (Coord.), Retos y Desafios del contrato de seguro: Del necesario aggiornamento a la metamorfosis del contrato. Libro homenaje al profesor Rubén Stiglitz, Cátedra Uría Menéndez - ICADE de Regulación de los Mercados. Parte III. Protección de consumidores, Thomson Reuters, Navarra, 2020, pp. 589-612.

Pizarro, Carlos, "Facultad de dejar sin efecto, modificar a su solo arbitrio, o suspender unilateralmente la ejecución del contrato", en: De La MAZA, I., Pizarro, C., (Dirs), La protección de los derechos de los consumidores. Comentarios a la ley de protección a los derechos de los consumidores, Thomson Reuters, Santiago, 2013, pp. 305-311.

Ríos, Roberto, "Comentarios Art. 542 del Cco", en: Ríos, R., (Dir.) El Contrato de Seguro Comentarios al Título VIII, Libro II del Código de Comercio, Thomson Reuters, Santiago, 2015. 
Ríos, Roberto, "La imperatividad de las normas que regulan el contrato de seguro en el ordenamiento jurídico chileno y el control de contenido del contrato: ¿Cambio radical en el sistema de aseguramiento?”, en: JEQuier, E., (Coord.), Estudios de Derecho Comercial, Cuartas Jornadas Chilenas de Derecho Comercial, Thomson Reuters - La Ley, Legal Publishing, Santiago, 2014, pp. 4951.

Ríos, Roberto, "La imperatividad en la regulación del contrato de seguro", Revista Española de Seguros, 2019, № 178, pp. 185-205.

RuBio, Francisco, "Elementos para la armonización de la legislación de seguros y de consumo en la protección del consumidor de seguros", Revista de Derecho y Consumo (Fundación Fernando Fueyo), 2019, N³, pp. 9-49.

Ruiz Tagle, Carlos, "La imperatividad como nuevo desafío de la institucionalidad del seguro chilena", Revista Chilena de Derecho de Seguros, 2015, No 24 , pp. 67-84.

TiRADO, Francisco, "La crisis del principio de la libre selección de asegurados. La cobertura de los menores, discapacitados, de los mayores y de determinados enfermos", en: Veiga, A., (Dir.), Martínez, M., (Coord.), Retos y Desafios del contrato de seguro: Del necesario aggiornamento a la metamorfosis del contrato. Libro homenaje al profesor Rubén Stiglitz, Cátedra Uría Menéndez - ICADE de Regulación de los Mercados. Parte III. Protección de consumidores, Thomson Reuters, Navarra, 2020, pp. 433-471.

Toso, Ángela, "Comentario al artículo 577 del Ccio", en: Ríos, R., (Dir) El Contrato de Seguro Comentarios al Título VIII, Libro II del Código de Comercio, Thomson Reuters, Santiago, 2015.

VÁsquez, Daniel, "La cargas de establecer las exclusiones el contrato de seguro en la primera página de la póliza", Rev. Ibero-Latinoam. Seguros, 2020, Vol. 29 (53), pp. 15-38.

VÁsqueZ, María Fernanda, "Solución de conflictos en el contrato de seguro: algunos problemas que se plantean a partir del sistema actual y su coexistencia con el régimen de consumo. Una propuesta de interpretación y reconstrucción", Revista de Derecho Universidad de Concepción, 2018, Vol. 86, № 244, pp. 129-176.

VÁsquez, María Fernanda, Tratado de arbitraje en Chile, Thomson Reuters, Santiago, 2018.

VÁsquez, María Fernanda, Contrato de Seguro. Doctrina y jurisprudencia, Tirant lo Blanch, Valencia, 2019.

Veiga, Abel, El Seguro. Hacia una reconfiguración del contrato, Cuadernos Civitas, Thomson Reuters, Navarra, 2018.

Veiga, Abel, Tratado del Contrato de Seguro, Thomson Reuters, Pamplona, 2014, $6^{\circ}$ Edición., T.1.

ZaRANTE, Gabriela, "Constitucionalización y protección de derechos fundamentales en el contrato de seguros. Análisis jurisprudencial - Corte 
constitucional de Colombia", Revista Ibero-Latinoamericana De Seguros, 2016, Vol. 25 (45), pp. 233-268

VeIgA, Abel, "Hacia una Europóliza. Los principios de derecho europeo del contrato de seguro", RIS (Bogotá), 2012, 37 (21), pp. 61-95.

Veiga, Abel, Productos financieros y seguro. Más allá del riesgo de inversión ¿Quo Vadis?, Thomson Reuters, Navarra, 2020.

\section{b) Normativa}

Código Civil, 1857.

Código de Comercio, 1865.

Código de Seguros (Francia).

Constitución Política de la República de Chile, 1980.

Convención de las Naciones Unidas sobre Compraventa Internacional de Mercaderías, adoptada en Viena en 1980 y elaborada en el seno de la Comisión de las Naciones Unidas para el Derecho Mercantil Internacional), 1990.

DFL N ${ }^{\circ} 251$, Sobre compañías de seguros, sociedades anónimas y bolsas de comercio, 1931.

Directiva 2009/138/CE, Sobre el seguro de vida, el acceso a la actividad de seguro y de reaseguro y su ejercicio (Solvencia II), 2009 (Comunidades Europeas).

Directiva N ${ }^{\circ} 13 / 93$, de la Comunidad Económica Europea, 1993. 18.490,

Historia de la Ley $\mathrm{N}^{\mathrm{o}} 20.667$.

Ley de Seguro, 1930 (Francia).

Ley N $\mathrm{N}^{\circ} 21.000$, Crea la Comisión para el Mercado Financiero, 2017.

Ley N $50 / 1980$, De contrato de seguro, 1980 (España).

Ley $\mathrm{N}^{\circ}$ 17.418, 1967 (Argentina).

Ley No 18.046, Sobre Sociedades Anónimas, 1981.

Ley $\mathrm{N}^{0} 18.490$, Establece seguro obligatorio de accidentes personales causados por circulación de vehículos motorizados, 1986.

Ley $N^{\circ}$ 19.496, Establece Normas de Protección de los Derechos de los Consumidores, 1997.

Ley $\mathrm{N}^{\circ} 20.416$, fija normas especiales para empresas de menor tamaño, 2010.

Ley $\mathrm{N}^{\circ} 20.555$, Modifica Ley $\mathrm{N}^{\circ} 19.496$, sobre protección de los derechos de los consumidores, para dotar de atribuciones en materias financieras, entre otras, al Servicio Nacional Del Consumidor, 2011.

Ley N $\mathrm{N}^{\circ} 20.667$, Regula el contrato se seguro, 2013.

Ley sobre contrato de seguro, 2007 (Alemania).

Primera Directiva 73/239/CEE, sobre coordinación de las disposiciones legales, reglamentarias y administrativas relativas al acceso a la actividad del seguro directo distinto del seguro de vida, y a su ejercicio, 1973 (Comunidades Europeas).

Principios Europeos del Derecho de los contratos (PECL), 2002. 
Principios Unidroit sobre los contratos comerciales internacionales, 2016.

Reglamento (CE) No 593/2008 del Parlamento Europeo y del Consejo sobre La Ley Aplicable a las Obligaciones Contractuales (Roma I), 2008.

\section{c) Normas administrativas}

NCG $\mathrm{N}^{\circ} 349$, Establece normas relativa al depósito de pólizas y disposiciones mínimas de las pólizas de seguros. Deroga Norma de Carácter General Nº 124, 2011.

NCG $\mathrm{N}^{\circ} 420$, que establece autoevaluación de principios de conducta de mercado en entidades aseguradoras y corredores de seguros. CMF, 2017.

Resolución Exenta N¹69, 2014

\section{d) Jurisprudencia}

Corte de Apelaciones de Antofagasta, 7 de mayo de 2015, Rol No 48-2015. 2013.

Corte de Apelaciones de Concepción, 19 de junio de 2014, Rol No 19350 -

Corte de Apelaciones de Concepción, 19 de junio de 2014, Rol № 194172013.

Corte Suprema, 21 de enero de 2019, Rol No 34507-2017.

Corte Suprema, 24 de junio de 2011, Rol No 6297-2009.

Juzgado de Policía Local de Vitacura, 15 de enero de 2018, Rol Nº25-72415.

Resolución Reclamo 02-1532-2012 (Iván Quezada Viera en contra de MAPFRE Compañía de Seguros Generales de Chile S.A.).

Tribunal Constitucional Español, 11 de enero de 2018, Rol No 1/18.

Tribunal Constitucional, 13 de mayo de 2008, Rol No 980-07.

Tribunal Supremo Español, 29 de enero de 2019, Rol No (no se indica): https://elderecho.com/clausulas-delimitacion-cobertura-clausulas-limitativasderechos-contrato-seguro, consultada: 15 de junio de 2021.

Tribunal Supremo Español, Rol $N^{o}$ (no se indica), 12 de diciembre de 2019: https://www.mundojuridico.info/delimitacion-de-cobertura-y-clausulaslimitativas-en-el-contrato-de-seguro/: 15 de junio de 2021. 